\title{
A Semianalytical Solution for Passively Loaded Piles Adjacent to Surcharge Load
}

\author{
Hao Zhang $\mathbb{D}^{1}{ }^{1}$ Minglei Shi, ${ }^{2}$ Lei Yang, ${ }^{3}$ and Yuancheng Guo ${ }^{1}$ \\ ${ }^{1}$ School of Civil Engineering, Zhengzhou University, Zhengzhou, Henan 450001, China \\ ${ }^{2}$ School of Transportation, Southeast University, Nanjing, Jiangsu 210096, China \\ ${ }^{3}$ Henan Information and Statistics Vocational College, Zhengzhou, Henan 450008, China \\ Correspondence should be addressed to Hao Zhang; tmzhanghao@zzu.edu.cn
}

Received 29 July 2019; Accepted 17 February 2020; Published 10 June 2020

Academic Editor: Claudio Mazzotti

Copyright ( $\odot 2020$ Hao Zhang et al. This is an open access article distributed under the Creative Commons Attribution License, which permits unrestricted use, distribution, and reproduction in any medium, provided the original work is properly cited.

Piles adjacent to a surcharge load commonly support not only active loads from superstructures but also the passive loads caused by soil lateral movement. To investigate the influence of passive load and the response along pile shafts of existing actively loaded piles, a load transfer model for analyzing the soil-pile interaction was developed based on plastic deformation theory and the triparameter soil model. An analytical solution for the deformation and internal force of such piles was proposed using the transfer matrix method, in which the transfer matrix coefficients for piles in free, plastic, and elastic zones were analytically obtained by considering the second-order axial force effect caused by lateral loading and soil yielding based on the triparameter soil model. The proposed methodology was validated by comparing its predictions with field measurements and previously published results. A good match between model predictions, field measurements, and previously published results implies that the proposed method can be used to evaluate the response of passive piles adjacent to a surcharge load. Parametric studies were also carried out to investigate the influence of surcharge pressure, soil resistance, and boundary conditions on the behavior of passively loaded piles adjacent to a surcharge load.

\section{Introduction}

Piles below existing buildings are commonly subjected to additional passive loading from moving soil caused by, for example, the construction of road embankments or fills adjacent to buildings. These piles are commonly classified as passive piles $[1,2]$. Passive loading can be significant, particularly for soft soil deposits and large lateral soil displacement which can induce changes in pile bearing and deformation characteristics. Vertically loaded piles originally designed according to the pile bearing capacity and settlement control may become piles controlled by lateral passive loading, which is commonly neglected and often causes engineering accidents, such as the collapse of the Shanghai BaoGang Steel Warehouse caused by a steel slag surcharge in 1998 [3, 4], and the toppling of a nearly finished 13-story residential building in Shanghai due to an excess surface load to the north and an excavation to the south in 2009 [5].
Proper consideration of the reaction of passive piles to surcharge load is the key to avoid such accidents. Numerous numerical and theoretical methods have been developed to analyze passive piles [6-8]. Numerical methods usually utilize the finite-element method $[9,10]$ or the finite difference method [11], which can consider complex boundary conditions and geological profiles but requires significant computational capacity and longer time. Theoretical methods can be categorized as displacement-based methods and pressure-based methods [12]. The displacement-based methods can better reflect the field behavior of piles due to soil movements by using free-field soil displacements to determine the soil-pile interaction forces $[9,13,14]$. However, a complex numerical simulation or a large number of field data is needed to determine the free-field soil displacements in advance, which increases the difficulty of applying the displacement-based method in engineering practice [1, 15]. The pressure-based methods assume the distribution of passive loading induced by lateral soil 
displacements based on laboratory tests or theoretical analyses and calculate the deflection and bending moment of the laterally loaded pile [16-19]. The availability of analytical solutions for laterally loaded piles makes the pressure-based methods more practical.

The capacity of the pressure-based methods to reflect the real passive pile behavior is closely related to the load transfer model employed for predicting the soil-pile interactions. Different soil-pile interaction models have been proposed to evaluate the responses of laterally loaded pile [20-24]. For passively loaded piles, Ito et al. proposed a theoretical method for analyzing the growth mechanism of lateral forces acting on stabilizing piles based on plastic deformation theory [25]. A special boundary condition (the lateral pressure between piles was assumed to be the active Earth pressure) was used to derive the passive load, which may result in the lateral soil pressure in the plastic zone different from the actual soil pressure [26]. Shen presented a limit analysis method in which the soil-pile interaction was analyzed using a plane-strain slip-line theory to consider the soil plastic flow around the piles [27]. Ashour et al. extended the strain wedge (SW) model and deduced the mobilized nonuniformly distributed passive load based on soil-pile interaction in an incremental fashion [16]. However, these studies are primarily about stabilizing piles which have no active loading and cannot be applied to the passively loaded piles adjacent to surcharge load.

Therefore, this paper aims to develop a semianalytical solution for passively loaded piles adjacent to surcharge load (i.e., the piles subjected to both active loading from superstructure and passive loading from adjacent surcharge load). Specifically, a load transfer model for soil-pile interactions is proposed using plastic deformation theory and the triparameter soil model. The passive load induced by a neighboring surcharge load was determined in an incremental fashion. Then, the deformation and internal force solutions for piles under combined active and passive loads were derived using the transfer matrix method. The proposed methodology was validated by comparing its predictions with field measurements and previously published results. Finally, parametric studies were carried out to investigate the influence of surcharge pressure, soil resistance, and boundary conditions.

\section{New Method for Analysis of Piles under Both Active and Passive Loadings}

2.1. Problem Definition. The problem addressed in this study is schematically shown in Figure 1(a) where the pile is subjected to both the active loading from the superstructure and the passive loading from the adjacent surcharge load, such as an embankment. The pile is embedded in a multilayered soil deposit with $n$ sublayers and has length $L$, diameter $d$, and bending stiffness EI. The pile has length $L_{a}$ and $L_{b}$ above and below the ground surface, respectively. The embedded part is divided into $n$ segments according to the $n$ soil layers. The active loads from the structure include the horizontal force $V_{0}$, moment $M_{0}$, and axial load $N_{0}$ acting on the pile head. A distributed load $q(z)$ acting on the pile above the ground surface (called the free zone) is considered to simulate the extra external loading from, for example, wind or wave. The pile is also subjected to a passive load $P_{s}(z)$ below the ground surface induced by nearby surcharge loading, which will be determined in Section 2.2.

Under the combined active and passive loads, the pile deforms continuously and may push the surrounding soil to its limit state. The soil begins to yield at the ground surface and extends downward, although the rest of the soil along the pile is still in an elastic state, and thus the soil state along the pile shaft can be divided into plastic and elastic zones (Figure 1(b)) [22, 28]. The reaction of the soil is denoted by a series of spring-slider elements (which are deactivated in the elastic state) along the shaft and each element is described by an elastic-perfectly plastic curve.

The influence of axial loads on the response of this passively loaded pile is also considered. An empirical axial force distribution on the pile shaft [29-31] is used to simulate the distribution of axial forces along the pile shaft in a multilayered soil deposit,

For the above ground portion of the pile, the axial force is expressed by

$$
N(x)=N_{0}+\eta z
$$

where $\eta\left(=A_{\mathrm{p}} \gamma_{\mathrm{G}}\right)$ is a coefficient describing the increase in axial force along the pile in the free zone due to the weight of the pile and $A_{\mathrm{p}}$ and $\gamma_{\mathrm{p}}$ represent the cross-sectional area and the unit weight of the pile, respectively.

For the pile below the ground, the axial force is assumed to vary with depth as follows:

$$
N_{i}(z)=N_{i-1}\left(\frac{1-\psi_{i}}{L_{b}}\right),
$$

where $N_{i-1}$ is the axial force at the bottom of the pile section in the $(i-1)$ th soil layer and $\psi_{i}$ is a coefficient dependent on skin friction mobilization in the soil.

2.2. Load Transfer Model of Soil-Pile Interaction. The model for analyzing soil-pile interactions of existing piles adjacent to a surcharge load is developed following the model of Ito et al. [25]. The soil-pile interaction growth mechanism is shown in Figure 2. With increasing adjacent surcharge pressure, the lateral stress $P_{B B^{\prime}}$ acting on surface $B B^{\prime}$ in front of pile increases and causes plastic deformation of the soil. For the load transfer between moving soil and piles, the plastic soil is assumed to start from surface $B B^{\prime}$ and extends to surface $O O^{\prime}$ where the lateral stress may equal the static Earth pressure $P_{0}$ in considering long-term soil consolidation [26], as shown in Figure 2. The plastic deformation zone in the soil continues to develop with increasing lateral stress $P_{B B^{\prime}}$ acting on surface $B B^{\prime}$ (Figures 2(a) and 2(c)). When the lateral stress acting on surface $B B^{\prime}$ increases sufficiently, soil is plastically deformed at the front and back of the piles (Figure 2(d)).

In order to analyze the load transfer between the moving soil and pile, the following assumptions are made (Figure 2(d)): 


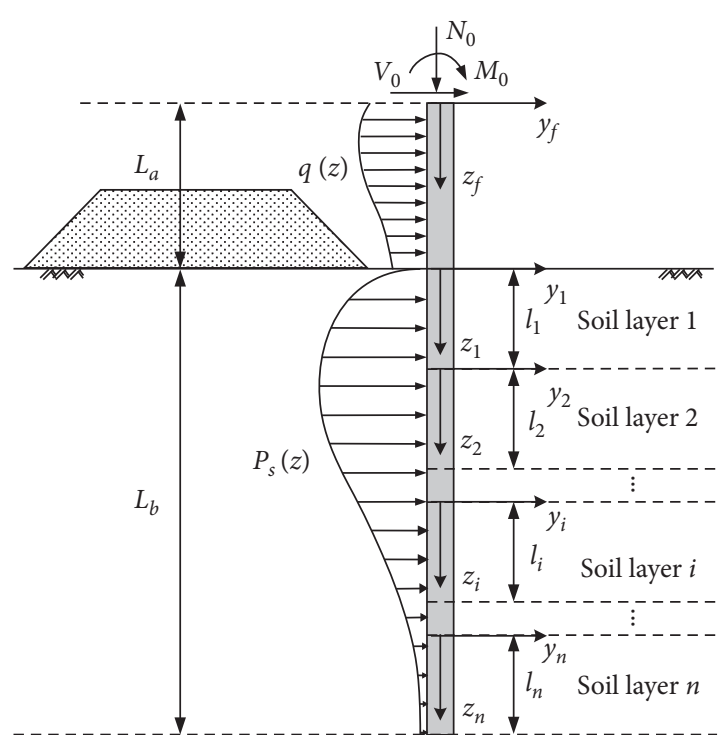

(a)

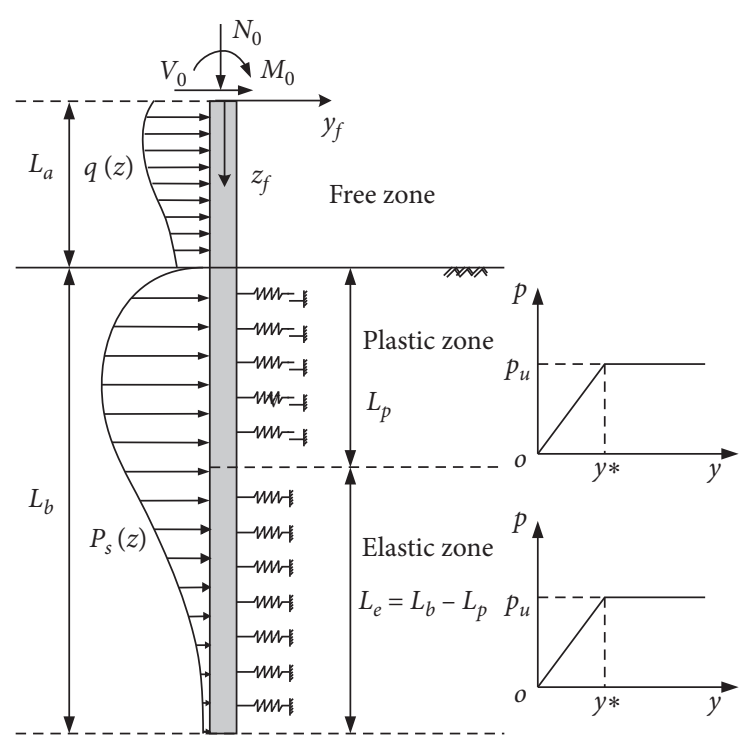

(b)

Figure 1: Pile subjected to both active and passive loading. (a) Problem statement. (b) Free, plastic, and elastic zones.

(a) The soil layer operates under plane-strain conditions in regard to depth. When the soil moves laterally, two sliding surfaces occur along lines $B E D G$ and $B^{\prime} E^{\prime} D^{\prime} G^{\prime}$, in which lines $E B$ and $E^{\prime} B^{\prime}$ make an angle $\pi / 4+\varphi / 2$ with the $x$-axis, and lines $D G$ and $D^{\prime} G^{\prime}$ make an angle $\pi / 4-\varphi / 2$ with the $x$-axis.

(b) Soil in $B E D G G^{\prime} D^{\prime} E^{\prime} B^{\prime}$ becomes plastic and obeys the Mohr-Coulomb yield criterion. The soil layer is represented as a plastic solid with an angle of internal friction $\varphi$ and cohesion $c$.

(c) Even if frictional forces act on surfaces $B E D G$ and $B^{\prime} E^{\prime} D^{\prime} G^{\prime}$, the stress distribution in soil $B E D G G^{\prime} D^{\prime} E^{\prime} B^{\prime}$ is almost the same as if no frictional forces on those surfaces exist. (d) Piles are rigid.

The lateral stress at any point in $B B^{\prime} E^{\prime} E, E E^{\prime} A^{\prime} A$, $A A^{\prime} D^{\prime} D$, and $D D^{\prime} G^{\prime} G$ can be obtained from "Appendix A" and expressed as follows:

In the $B B^{\prime} E^{\prime} E$ zone,

$$
\sigma_{x}^{I}=\frac{1}{G_{1}}\left\{\left[\frac{D_{I}(x)}{D_{1}}\right]^{G_{1}} \cdot\left[G_{1} \cdot P_{B B^{\prime}}(z)+c \cdot G_{2}\right]-c \cdot G_{2}\right\} \text {. }
$$

In the $E E^{\prime} A^{\prime} A$ zone,

$$
\sigma_{x}^{\mathrm{II}}=\frac{\left(D_{2} / D_{1}\right)^{G_{1}}\left[G_{1} \cdot P_{B B^{\prime}}(z)+c \cdot G_{2}\right]-c \cdot G_{2}}{G_{1} \cdot \exp \left[\left(2 x N_{\varphi} \tan \varphi+d G_{3}\right) / D_{2}\right]}+\frac{c \cdot\left(2 N_{\varphi}^{1 / 2} \tan \varphi+1\right)}{N_{\varphi} \tan \varphi \exp \left[\left(2 x N_{\varphi} \tan \varphi+d G_{3}\right) / D_{2}\right]-c \cdot\left(2 N_{\varphi}^{1 / 2} \tan \varphi+1\right) / N_{\varphi} \tan \varphi .}
$$

In the $A A^{\prime} D^{\prime} D$ zone,

$\sigma_{x}^{\mathrm{III}}=\frac{P_{A A^{\prime}}(z) N_{\varphi}^{\prime} \tan \varphi-c\left(2 N_{\varphi}^{\prime} 1 / 2 \tan \varphi-1\right)}{N_{\varphi}^{\prime} \tan \varphi \exp \left(2 x N_{\varphi}^{\prime} \tan \varphi / D_{2}\right)}+\frac{c\left(2 N_{\varphi}^{\prime 1 / 2} \tan \varphi-1\right)}{N_{\varphi}^{\prime} \tan \varphi}$.

$$
\begin{aligned}
\sigma_{x}^{\mathrm{IV}}= & {\left[\frac{D_{\mathrm{IV}}(x)}{D_{2}}\right]^{H_{1}} \cdot\left[\frac{P_{A A^{\prime}}(z) N_{\varphi}^{\prime} \tan \varphi-2 c N_{\varphi}^{\prime \prime / 2} \tan \varphi+1}{N_{\varphi}^{\prime} \tan \varphi \exp \left(d H_{3} / D_{2}\right)}\right.} \\
& \left.+\frac{c\left(2 N_{\varphi}^{\prime 1 / 2} \tan \varphi-1\right)}{N_{\varphi}^{\prime} \tan \varphi}-\frac{c H_{2}}{H_{1}}\right]+\frac{c H_{2}}{H_{1}},
\end{aligned}
$$

In the $D D^{\prime} G^{\prime} G$ zone, 


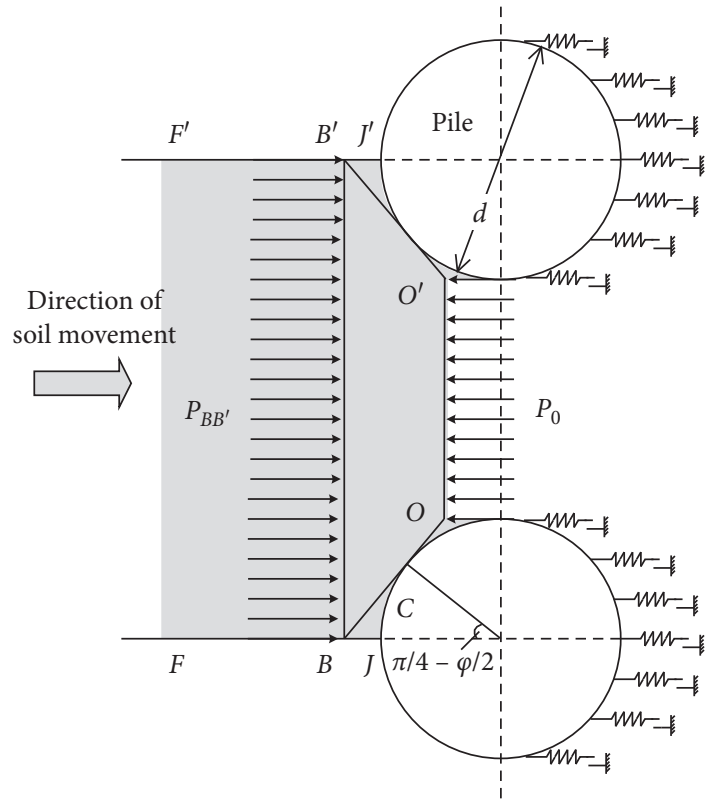

(a)

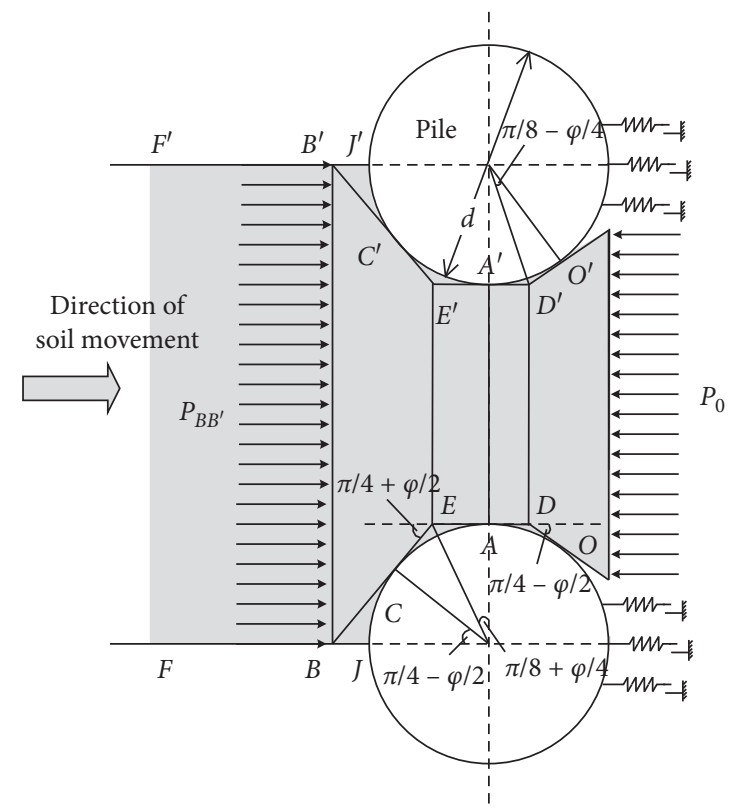

(c)

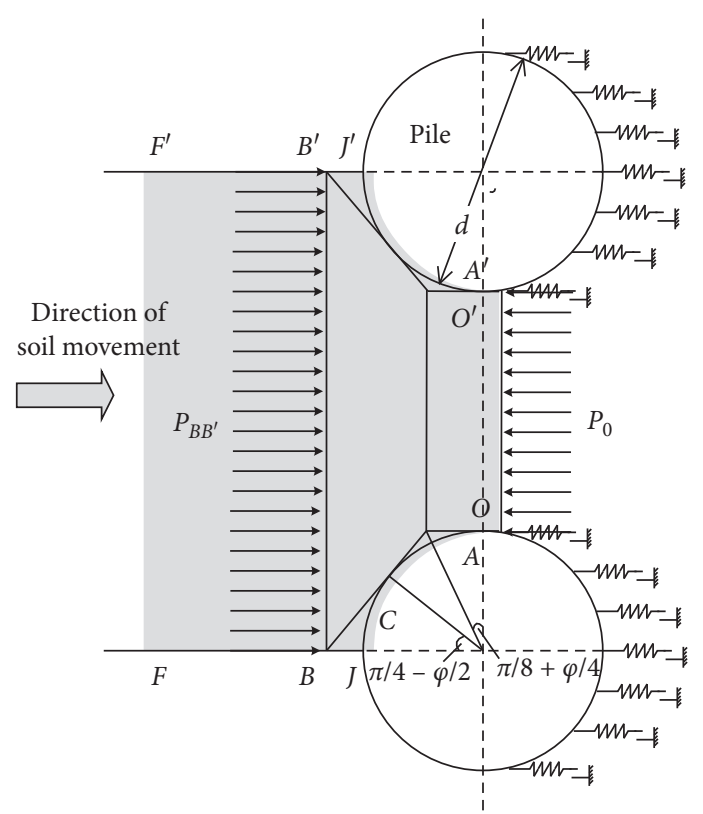

(b)

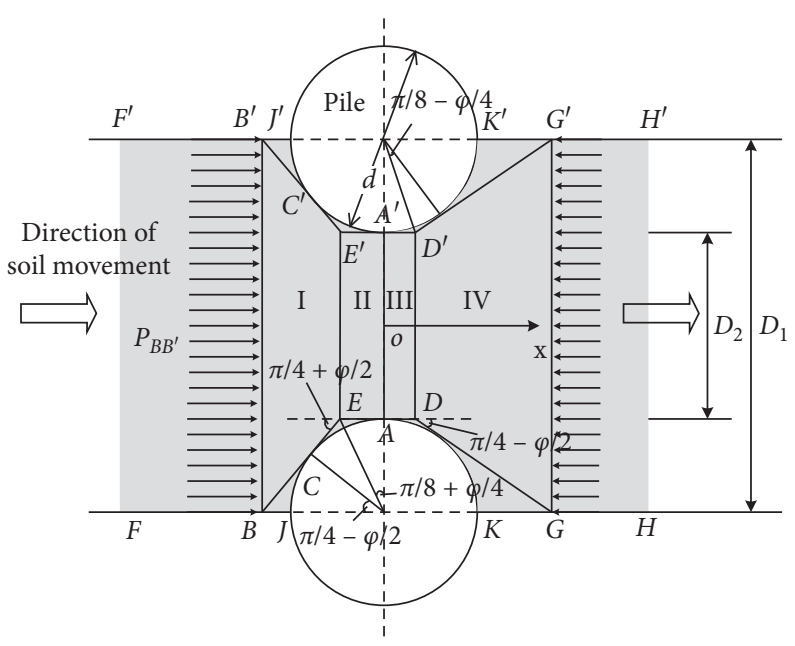

(d)

Figure 2: Soil-pile load transfer model. Plastic deformation zone (a) just before the piles, (b) developing to the middle of the piles (c) developing to the rear of the piles, and (d) all through the piles.

where $\sigma_{x}^{\mathrm{I}}, \sigma_{x}^{\mathrm{II}}, \sigma_{x}^{\mathrm{III}}$, and $\sigma_{x}^{\mathrm{IV}}$ are the lateral stress at any point $x$ in the $B B^{\prime} E^{\prime} E$ zone, $E E^{\prime} A^{\prime} A$ zone, $A A^{\prime} D^{\prime} D$ zone, and $D D^{\prime} G^{\prime} G$ zone, respectively; $D_{1}$ is pile spacing; $D_{2}$ is net spacing between piles; $N_{\varphi}=\tan ^{2}((\pi / 4)+(\varphi / 2)) ; N_{\varphi}^{\prime}=\tan ^{2}((\pi / 4)-$ $(\varphi / 2)) ; G_{1}=N_{\varphi}^{1 / 2} \tan \varphi+N_{\varphi}-1 ; G_{2}=2 \tan \varphi+2 N_{\varphi}^{1 / 2}+N_{\varphi}^{-1 / 2} ;$ $G_{3}=N_{\varphi} \tan \varphi \tan ((\pi / 8)+(\varphi / 4)) ; \quad H_{1}=N_{\varphi}^{\prime}-N_{\varphi}^{\prime}{ }_{\varphi}^{\prime / 2} \tan \varphi-1 ;$ $H_{2}=2 N_{\varphi}^{\prime 1 / 2}+2 \tan \varphi-N_{\varphi}^{\prime-1 / 2} ; \quad H_{3}=N_{\varphi}^{\prime} \tan \varphi \tan ((\pi / 8)-$ $(\varphi / 4)) ; \quad D_{\mathrm{I}}(x)=D_{2}-2[x+(d / 2) \tan ((\pi / 8)+(\varphi / 4))] N_{\varphi}^{1 / 2}$; $D_{\mathrm{IV}}(x)=D_{2}+2[x-(d / 2) \tan ((\pi / 8)-(\varphi / 4))] N_{\varphi}^{\prime 1 / 2}$.
$P_{B B^{\prime}}(z)$ is the total soil pressure acting on surface $B B^{\prime}$ which is given by

$$
P_{B B^{\prime}}(z)=\overline{\sigma_{x}}(z)+K_{0} \gamma z
$$

where $\overline{\sigma_{x}}(z)$ is the additional lateral stress acting on surface $B B^{\prime}$ induced by the surcharge load and can be estimated using Boussinesq's solution and the Flamant integral solution according to the distribution characteristics of 
surcharge load $[26,32] ; K_{0}$ is the static Earth pressure coefficient.
$P_{A A^{\prime}}(z)$ is the lateral stress acting on the surface $A A^{\prime}$ which is given by (Appendix A)

$$
P_{A A^{\prime}}(z)=\frac{\left(D_{2} / D_{1}\right)^{G_{1}}\left[G_{1} \cdot P_{B B^{\prime}}(z)+c \cdot G_{2}\right]-c \cdot G_{2}}{G_{1} \cdot \exp \left(d G_{3} / D_{2}\right)}+\frac{c \cdot\left(2 N_{\varphi}^{1 / 2} \tan \varphi+1\right)}{N_{\varphi} \tan \varphi \exp \left(d G_{3} / D_{2}\right)}-\frac{c \cdot\left(2 N_{\varphi}^{1 / 2} \tan \varphi+1\right)}{N_{\varphi} \tan \varphi}
$$

The passive load $P_{s}(z)$ acting on piles induced by moving soil can be obtained by the following steps:

(a) Using (7), the total soil pressure $P_{B B^{\prime}}(z)$ acting on surface $B B^{\prime}$ can be obtained. Then, the lateral stress $P_{A A^{\prime}}(z)$ acting on surface $A A^{\prime}$ can be obtained using (8).

(b) When $P_{A A^{\prime}}(z) \leq P_{0}=K_{0} \gamma z$, substituting $\sigma_{x}^{\mathrm{I}}=K_{0} \gamma z$ into (3), $x=x_{o}$ can be obtained. If $x_{o}$ is in zone $B B^{\prime} E^{\prime} E(-(d / 2) / \cos ((\pi / 4)-(\varphi / 2)) \leq x \leq-(d / 2) \tan$ $((\pi / 8)+(\varphi / 4)))$, as given by the condition in $(3)$, the passive load acting on piles can be calculated by

$$
P_{s}(z)=P_{B B^{\prime}}(z) D_{1}-\left.\sigma_{x}^{\mathrm{I}}\right|_{x=x_{o}} D_{\mathrm{I}}\left(x_{o}\right)
$$

Otherwise, $x=x_{o}$ can be obtained by substituting $\sigma_{x}^{\mathrm{II}}=$ $K_{0} \gamma z$ into (4). The passive load acting on piles can be calculated by

$$
P_{s}(z)=P_{B B^{\prime}}(z) D_{1}-\left.\sigma_{x}^{\mathrm{II}}\right|_{x=x_{o}} D_{2} \text {. }
$$

(c) When $P_{A A^{\prime}}(z)>P_{0}=K_{0} \gamma z$, substituting $\sigma_{x}^{\mathrm{III}}=K_{0} \gamma z$ into (5), it gives $x=x_{o} \quad(-(d / 2) \tan ((\pi / 8)+$ $(\varphi / 4)) \leq x \leq 0))$. If $x_{o}$ is in zone $A A^{\prime} D^{\prime} D$ $(0<x \leq(d / 2) \tan ((\pi / 8)-(\varphi / 4)))$, as given by the condition in (5), the passive load acting on piles can be calculated by

$$
P_{s}(z)=P_{B B^{\prime}}(z) D_{1}-\left.\sigma_{x}^{\mathrm{III}}\right|_{x=x_{o}} D_{2} \text {. }
$$

Otherwise, $x=x_{o}$ can be obtained by substituting $\sigma_{x}^{\mathrm{IV}}=$ $K_{0} \gamma z$ into (6). If $(d / 2) \tan ((\pi / 8)-(\varphi / 4))<x_{o} \leq(d / 2) /$ $\cos ((\pi / 4)+(\varphi / 2))$, as given by the condition in (6), the passive load acting on piles can be calculated by

$$
P_{s}(z)=P_{B B^{\prime}}(z) D_{1}-\left.\sigma_{x}^{\mathrm{IV}}\right|_{x=x_{o}} D_{\mathrm{IV}}\left(x_{o}\right) \text {. }
$$

If $x_{o}>(d / 2) / \cos ((\pi / 4)+(\varphi / 2))$, the passive load acting on piles can be calculated by

$$
P_{s}(z)=P_{B B^{\prime}}(z) D_{1}-\left.\sigma_{x}^{\mathrm{IV}}\right|_{x=(d / 2) / \cos ((\pi / 4)+(\varphi / 2))} \cdot D_{1} .
$$

The soil resistance behind the piles can be represented by springs for evaluating pile response, which is simulated using a perfectly elastic-plastic model. The reaction of the soil behind piles can be described as

$$
p=\left\{\begin{array}{l}
\delta b_{1} k y, \quad y<y_{*}, \\
p_{u}=\delta b_{1} k y_{*}, \quad y \geq y_{*}
\end{array}\right.
$$

where $k$ is the soil reaction modulus. $k$ can be described using a triparameter soil model $k(z)=m\left(z_{0}+z\right)^{n}$, in which $m$ and $n$ are soil reaction modulus coefficients; $z_{0}$ is the initial height of the ground surface; $b_{1}$ is the calculated pile width; $p_{u}$ is ultimate soil resistance; $y$ is pile deflection; $y_{*}$ is ultimate soil displacement. According to Matlock, $y_{*}=20 \varepsilon_{c} d$ for clay and $y_{*}=3 d / 80$ for sand. $\varepsilon_{c}$ is the soil strain, and $\varepsilon_{c}=0.005-0.02[20]$.

$\delta$ is a correction coefficient for considering the influence of plastic soil deformation on the reaction calculated width of the soil behind the piles. When plastic soil deformation enters the $D D^{\prime} G^{\prime} G$ zone, the expansion of plastic deformation may decrease the reaction calculated width of the soil behind the piles (Figures 2(c) and 2(d)):

$$
\delta= \begin{cases}1, & -\frac{d / 2}{\cos (\pi / 4-\varphi / 2)} \leq x \leq \frac{d}{2} \tan \left(\frac{\pi}{8}-\frac{\varphi}{4}\right), \\ \frac{D_{1}-2 N_{\varphi}^{\prime} 1 / 2[x-(d / 2) \tan ((\pi / 8)-(\varphi / 4))]}{d}, & \frac{d}{2} \tan \left(\frac{\pi}{8}-\frac{\varphi}{4}\right)<x<\frac{d / 2}{\cos (\pi / 4+\varphi / 2)} \\ 0, & x \geq \frac{d / 2}{\cos (\pi / 4+\varphi / 2)} .\end{cases}
$$


2.3. Governing Differential Equations. Assuming the pile behaves as a Euler-Bernoulli beam, the differential equations governing pile deflection in the free, plastic, and elastic zones (Figure 1(b)) can be obtained by discretizing each pile segment into subslices. The accuracy of the solution is improved with finer pile slices.

For the pile in free zone above the ground surface, each pile slice has an individual coordinate system marked with the subscript $a$ (Figure 3(a)). The pile length $L_{a}$ is spilt into $n_{a}$ subslices with length $l_{a}=L_{a} / n_{a}$. The distributed lateral load acting on the $\kappa$ th pile slice can be calculated as the average of the load acting on the slice:

$$
\bar{q}_{a(\kappa)}=\frac{\left(q_{a(\kappa-1)}+q_{a(\kappa)}\right)}{2} .
$$

The average axial force of the $\kappa$ th slice for the pile in the free zone can be calculated using equation (1):

$$
\bar{N}_{a(\kappa)}=\frac{\left(N_{a(\kappa-1)}+N_{a(\kappa)}\right)}{2} \text {. }
$$

For the pile beneath the ground surface, the pile length $L_{b}$ is divided into $n$ segments by the soil layers. Each pile segment has its individual coordinate system marked with the subscript $i$ (Figures 3(b) and 3(c)) and is split into $n_{i}$ subslices. The average axial force on the pile slice can be calculated using equation (2):

$$
\bar{N}_{(i, w)}=\frac{\left(N_{(i, w-1)}+N_{(i, w)}\right)}{2},
$$

where the subscripts $i$ and $w$ refer to the $w$ th pile slice of the $i$ th pile segment in the $i$ th soil layer.

Based on equations (9) (13), the average passive load $\left(\bar{P}_{s(i, w)}\right)$ acting on the $w$ th pile slice of the $i$ th pile segment in the $i$ th soil layer can be calculated as the average load acting on the corresponding slice as follows:

$$
\bar{P}_{s(i, w)}=\frac{\left(P_{s(i, w-1)}+P_{s(i, w)}\right)}{2} .
$$

In the plastic zone, the average ultimate soil resistance behind the $w$ th pile slice of the ith pile segment, $\bar{p}_{u(i, w)}$, can be regarded as the average ultimate soil resistance of the top and bottom of the corresponding slice:

$$
\bar{p}_{u(i, w)}=\frac{\left(p_{u(i, w-1)}+p_{u(i, w)}\right)}{2} .
$$

Similarly in the elastic zone, linear elastoplastic spring models are used, and the average soil reaction modulus $\left(\bar{k}_{(i, w)}\right)$ behind the $w$ th pile slice of the ith pile segment can be calculated as the average soil reaction modulus of the top and bottom of the corresponding slice as

$$
\bar{k}_{(i, w)}=\frac{\left(k_{(i, w-1)}+k_{(i, w)}\right)}{2} .
$$

For the $\kappa$ th pile slice in the free zone (Figure 3(a)), the governing differential equation is

$$
E I_{a} \frac{\mathrm{d}^{4} y_{a(\kappa)}}{\mathrm{d} z_{a(\kappa)}}+\bar{N}_{a(\kappa)} \frac{\mathrm{d}^{2} y_{a(\kappa)}}{\mathrm{d} z_{a(\kappa)}{ }^{2}}-\bar{q}_{a(\kappa)}=0 .
$$

For the $w$ th pile slice of the $i$ th pile segment in the plastic zone (Figure $3(\mathrm{~b})$ ), the differential equation is

$$
E I_{i} \frac{\mathrm{d}^{4} y_{p(i, w)}}{\mathrm{d} z_{p(i, w)}}+\bar{N}_{(i, w)} \frac{\mathrm{d}^{2} y_{p(i, w)}}{\mathrm{d} z_{p(i, w)}{ }^{2}}+p_{u(i, w)}=\bar{P}_{s(i, w)},
$$

where the subscript $p$ indicates the plastic state.

When the soil resistance is in the elastic stage (Figure 3(c)), the differential equation can be expressed as

$$
E I_{i} \frac{\mathrm{d}^{4} y_{e(i, w)}}{\mathrm{d} z_{e(i, w)}}+\bar{N}_{(i, w)} \frac{\mathrm{d}^{2} y_{e(i, w)}}{\mathrm{d} z_{p(i, w)}{ }^{2}}+\delta b_{1} \bar{k}_{(i, w)} y_{e(i, w)}=\bar{P}_{s(i, w)},
$$

where the subscript $e$ indicates the plastic state.

2.4. Analysis for the Free Zone. Solving (22), the deflection of the $i$ th pile slice is given by

$$
\begin{aligned}
y_{a(\kappa)}= & C_{\mathrm{o} 1}+C_{\mathrm{o} 2} z_{a(\kappa)}+C_{\mathrm{o} 3} \cos \lambda_{a(\kappa)} z_{a(\kappa)}+C_{\mathrm{o} 4} \sin \lambda_{a(\kappa)} z_{a(\kappa)} \\
& +\frac{\bar{a}}{2 \lambda_{a(\kappa)}^{2}} z_{a(\kappa)}^{2},
\end{aligned}
$$

where $y_{a(\kappa)}$ is the pile deflection on the $\kappa$ th pile slice at depth $z_{a(\kappa)} ; \lambda_{a(\kappa)}^{2}=\bar{N}_{a(\kappa)} / E I_{a} ; \bar{a}=\bar{q}_{a(\kappa)} / E I_{a} ; C_{\mathrm{o} 1}, C_{\mathrm{o} 2}, C_{\mathrm{o} 3}$, and $\mathrm{C}_{\mathrm{O} 4}$ are integration constants.

Using equation (25), pile slope $\varphi_{a(\kappa)}$, bending moment $M_{a(\kappa)}$, and shear force $V_{a(\kappa)}$ at depth $z_{a(\kappa)}$ are given by

$$
\begin{aligned}
\varphi_{a(\kappa)} & =\frac{\mathrm{d} y_{a(\kappa)}}{\mathrm{d} z_{a(\kappa)}} ; \\
\frac{M_{a(\kappa)}}{E I_{a}} & =\frac{\mathrm{d}^{2} y_{a(\kappa)}}{\mathrm{d} z_{a(\kappa)}} ; \\
\frac{V_{a(\kappa)}}{E I_{a}} & =\frac{\mathrm{d} M_{a(\kappa)}}{\mathrm{d} z_{a(\kappa)}}+\lambda_{a(\kappa)} \frac{2}{\mathrm{~d} y_{a(\kappa)}} .
\end{aligned}
$$

The transfer matrix function of the $i$ th pile slice in the free zone can be expressed as

$$
\mathbf{U}_{a(\kappa)}=\mathbf{S}_{a(\kappa)} \cdot \mathbf{U}_{a(\kappa-1)},
$$

where $\mathbf{U}_{a(\kappa)}=\left[y_{a(\kappa)}, \varphi_{a(\kappa)}, M_{a(\kappa)}, V_{a(\kappa)}, 1\right]^{T} ; \quad y_{a(\kappa)}, \varphi_{a(\kappa)}$, $M_{a(\kappa)}$, and $V_{a(\kappa)}$ are the pile deflection, slope, bending moment, and shear force at the bottom of the $\kappa$ th pile slice in the free zone, respectively; $\mathbf{U}_{a(\kappa-1)}=\left[y_{a(\kappa-1)}, \varphi_{a(\kappa-1)}\right.$, $\left.M_{a(\kappa-1)}, V_{a(\kappa-1)}, 1\right]^{T} ; y_{a(\kappa-1)}, \varphi_{a(\kappa-1)}, M_{a(\kappa-1)}$, and $V_{a(\kappa-1)}$ are the pile deflection, slope, bending moment, and shear force at the top of the $\kappa$ th pile slice, respectively. slice: 


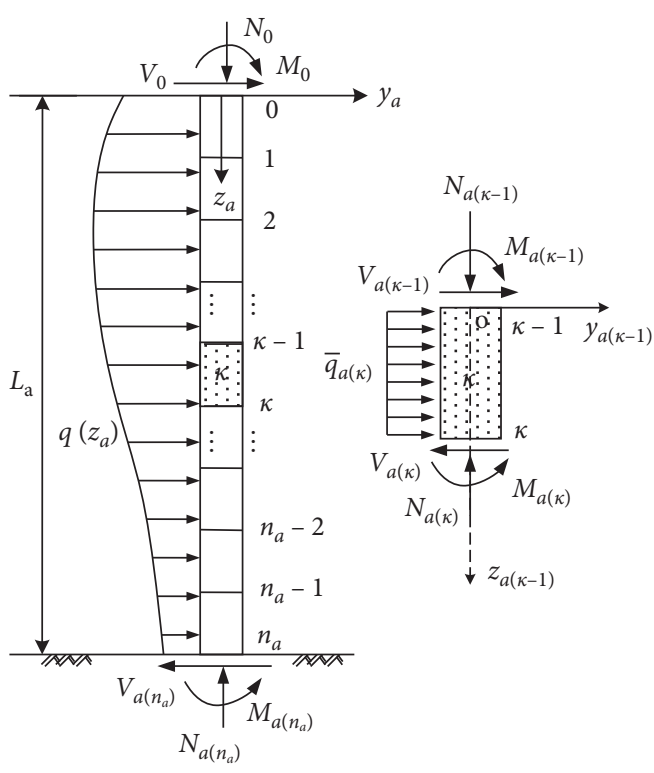

(a)

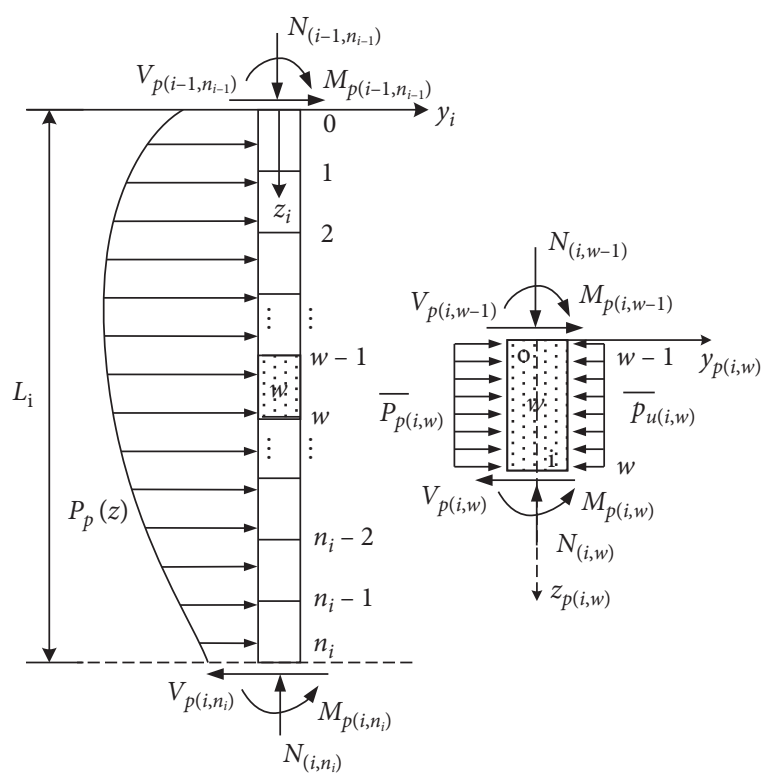

(b)

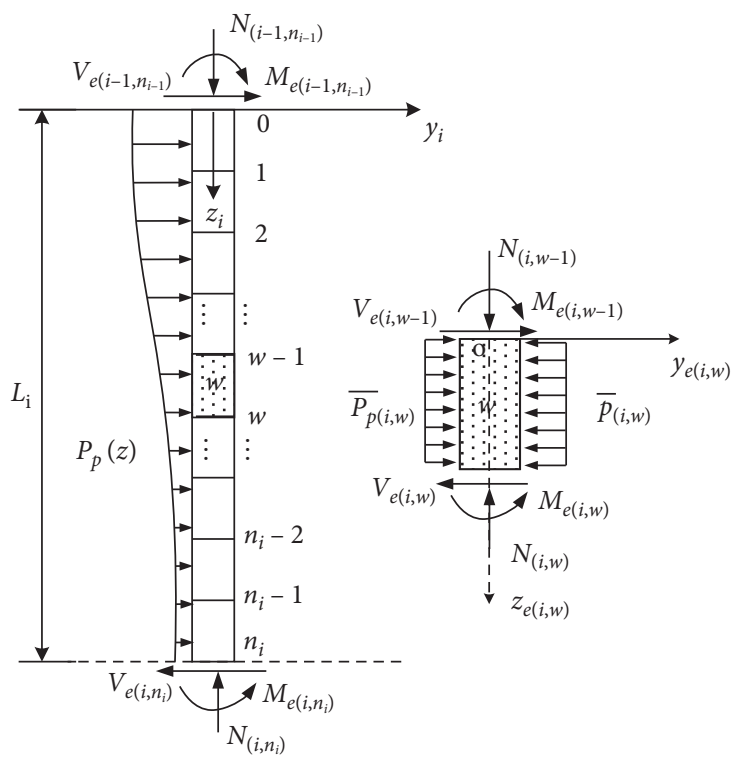

(c)

Figure 3: Pile discretization. (a) Free zone. (b) Soil in plastic state. (c) Soil in elastic state. 


$$
\mathbf{S}_{a(\kappa)}=\left[\begin{array}{ccccc}
A_{a 1} & \frac{B_{a 1}}{\lambda_{a(\kappa)}} & \frac{C_{a 1}}{\lambda_{a(\kappa)}{ }^{2} E I_{a}} \frac{D_{a 1}}{\lambda_{a(\kappa)}{ }^{3} E I_{a}} & E_{a 1} \\
\lambda_{a(\kappa)} A_{a 2} & B_{a 2} & \frac{C_{a 2}}{\lambda_{a(\kappa)} E I_{a}} & \frac{D_{a 2}}{\lambda_{a(\kappa)}{ }^{2} E I_{a}} & \lambda_{c} E_{a 2} \\
\lambda_{a(\kappa)}{ }^{2} E I_{a} A_{a 3} & \lambda_{a(\kappa)} E I_{a} B_{a 3} & C_{a 3} & \frac{D_{a 3}}{\lambda_{a(\kappa)}} & \lambda_{a(\kappa)}{ }^{2} E I_{a} E_{a 3} \\
\lambda_{a(\kappa)}{ }^{3} E I_{a} A_{a 4} & \lambda_{a(\kappa)}{ }^{2} E I_{a} B_{a 4} & \lambda_{a(\kappa)} C_{a 4} & D_{a 4} & \lambda_{a(\kappa)}{ }^{3} E I_{a} E_{a 4} \\
0 & 0 & 0 & 0 & 1
\end{array}\right],
$$

where $A_{a j}, B_{a j}, C_{a j}, D_{a j}$, and $E_{a j}(j=1-4)$ are 20 dimensionless coefficients, which are a function of $\lambda_{a(\kappa)} l_{a}$.

As a result, based on the deflection and stress continuity of the pile, the transfer matrix function for the pile segment in the free zone can be expressed as

$$
\mathbf{U}_{a\left(n_{a}\right)}=\mathbf{S}_{a\left(n_{a}\right)} \mathbf{S}_{a\left(n_{a}-1\right)} \cdots \mathbf{S}_{a(2)} \mathbf{S}_{a(1)} \mathbf{U}_{a(0)}=\mathbf{S}_{a} \mathbf{U}_{a(0)}=\mathbf{S}_{a} \mathbf{U}_{0},
$$

where $\mathbf{U}_{0}=\left[y_{0}, \varphi_{0}, M_{0}, V_{0}, 1\right]^{T}$ and $\mathbf{U}_{a\left(n_{a}\right)}=\left[y_{a\left(n_{a}\right)}, \varphi_{a\left(n_{a}\right)}\right.$, $\left.M_{a\left(n_{a}\right)}, V_{a\left(n_{a}\right)}, 1\right]^{T}$ are 5-by-1 transposed matrices and represent pile deflection, slope, bending moment, and shear force for the head and bottom of the pile segment in the free zone, respectively; $\mathbf{S}_{a}$ is the overall transfer matrix coefficient of the pile in the free zone.

2.5. Analysis for the Plastic Zone. In the plastic soil zone, as the passive load and ultimate soil resistance can be determined using equations (19) and (20), respectively; the form of equation (23) is similar to equation (22), and the solution methods for the two differential equations are similar. The transfer matrix function of equation (23) of the $w$ th pile slice of the $i$ th pile segment can be expressed as

$$
\mathbf{U}_{p(i, w)}=\mathbf{S}_{p(i, w)} \mathbf{U}_{p(i, w-1)}
$$

where $\mathbf{U}_{p(i, w)}=\left[y_{p(i, w)}, \varphi_{p(i, w)}, M_{p(i, w)}, V_{p(i, w)}, 1\right]^{T} ; y_{p(i, w)}$, $\varphi_{p(i, w)}, M_{p(i, w)}$, and $V_{p(i, w)}$ are the pile deflection, slope, bending moment, and shear force at the bottom of the $w$ th pile slice of the $i$ th pile segment; $\mathbf{U}_{p(i, w-1)}=\left[y_{p(i, w-1)}\right.$, $\left.\varphi_{p(i, w-1)}, M_{p(i, w-1)}, V_{p(i, w-1)}, 1\right]^{T} ; \quad y_{p(i, w-1)}, \quad \varphi_{p(i, w-1)}$, $M_{p(i, w-1)}$, and $V_{p(i, w-1)}$ are the pile deflection, slope, bending moment, and shear force at the head of $w$ th pile slice.

$\mathbf{S}_{p(i, w)}$ is the transfer matrix coefficient of the $w$ th pile slice of the $i$ th pile segment when the pile section is in the plastic zone. When $\lambda_{p(i, w)}{ }^{2}=\bar{N}_{(i, w)} / E I_{i}$,

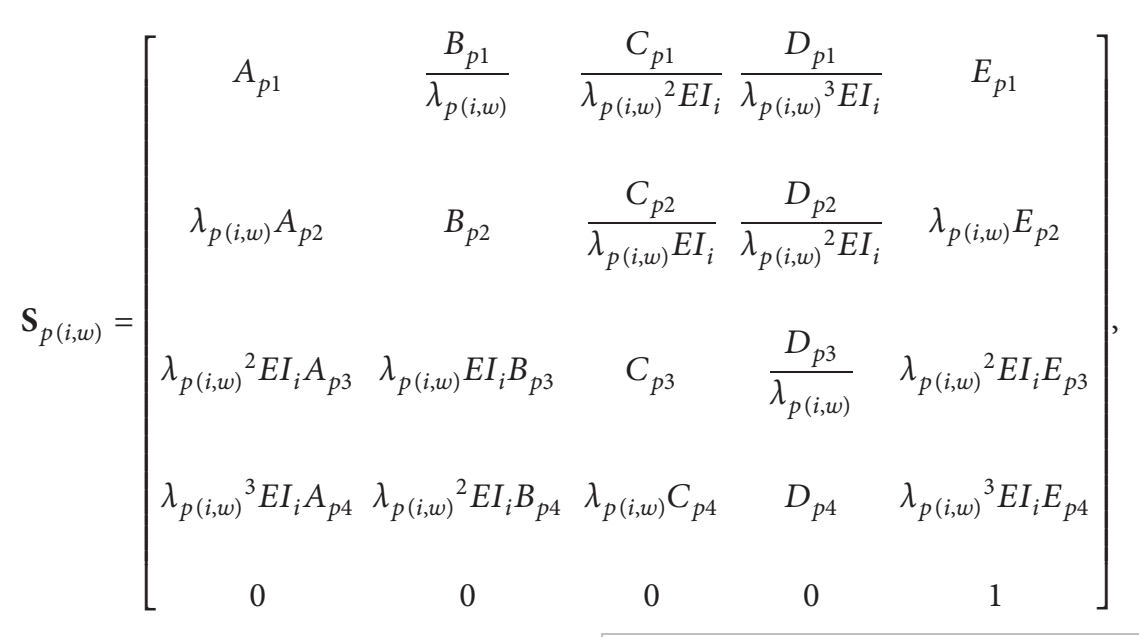

where $A_{p j}, B_{p j}, C_{p j}, D_{p j}$, and $E_{p j}(j=1-4)$ are 20 dimensionless coefficients, which are function of $\lambda_{p(i, w)} l_{i}$.

Assuming the pile in the plastic zone extends from the $s$ th slice of the $t$ th pile segment to the $u$ th pile slice of the $v$ th pile segment, the matrix transfer function for the pile in the plastic zone is given by

$$
\mathbf{U}_{p(v, u)}=\mathbf{S}_{p(v, u)} \mathbf{S}_{p(v, u-1)} \cdots \mathbf{S}_{p(t, s+1)} \mathbf{S}_{p(t, s)} \mathbf{U}_{p(t, s)}=\mathbf{S}_{p} \mathbf{U}_{p(t, s)},
$$


where $\mathbf{S}_{p}$ is the overall transfer matrix coefficient of the pile in the plastic zone.

2.6. Analysis of the Elastic Zone. Similarly for piles in the elastic soil zone, the deflection of the $w$ th pile slice of the $i$ th pile segment in the elastic zone can be obtained by solving equation (24).

$$
\text { When } \lambda_{e(i, w)}^{4} \geq 4 \alpha_{e(i, w)} 4 \text { or } \bar{N}_{(i, w)} \geq 2 \sqrt{E I_{i} \bar{k}_{(i, w)} \delta b_{1}} \text {, }
$$

$$
\begin{aligned}
y_{e(i, w)}= & C_{e 1} \cos \omega_{1 i} \lambda_{e(i, w)} z_{e(i, w)}+C_{e 2} \sin \omega_{1 i} \lambda_{e(i, w)} z_{e(i, w)} \\
& +C_{e 3} \cos \omega_{2 i} \lambda_{e(i, w)} z_{e(i, w)}+C_{e 4} \sin \omega_{2 i} \lambda_{e(i, w)} z_{e(i, w)} \\
& +\beta / \alpha_{e(i, w)} 4
\end{aligned}
$$

When $\lambda_{e(i, w)}{ }^{4}<4 \alpha_{e(i, w)} 4$ or $\bar{N}_{(i, w)}<2 \sqrt{E I_{i} \bar{k}_{(i, w)} \delta b_{1}}$,

$$
\begin{aligned}
& y_{e(i, w)}=C_{e 1} e^{\omega_{3} \lambda_{e(i, w)} z_{e(i, w)}} \cos \omega_{4} \lambda_{e(i, w)} z_{e(i, w)}+C_{e 2} e^{\omega_{3} \lambda_{e(i, w)} z_{e(i, w)}} \sin \omega_{4} \lambda_{e(i, w)} z_{e(i, w)}
\end{aligned}
$$

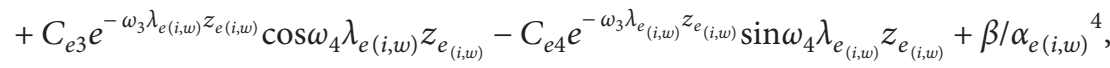

$$
\begin{aligned}
& \mathbf{U}_{e(i, w)}=\mathbf{S}_{e(i, w)} \mathbf{U}_{e(i, w-1)},
\end{aligned}
$$

where $\quad \lambda_{e(i, w)}{ }^{2}=\bar{N}_{(i, w)} / E I_{i} ; \quad \alpha_{e(i, w)}{ }^{4}=\delta b_{1} \bar{k}_{(i, w)} / E I_{i} ; \quad \beta=$ $\bar{P}_{s(i, w)} / E I_{i} . \quad \omega_{1}=\sqrt{1-\sqrt{1-4\left(\alpha_{e(i, w)} / \lambda_{e(i, w)}\right)^{4}} / 2} ; \quad \omega_{2}=$ $\sqrt{1+\sqrt{1-4\left(\alpha_{e(i, w)} / \lambda_{e(i, w)}\right)^{4}} / 2} ; \quad \omega_{3}=\sqrt{2\left(\alpha_{e(i, w)} / \lambda_{e(i, w)}\right)^{2}-1} / 2 ;$ $\omega_{4}=\sqrt{2\left(\alpha_{e(i, w)} / \lambda_{e(i, w)}\right)^{2}+1} / 2 ; C_{e 1}, C_{e 2}, C_{e 3}$, and $C_{e 4}$ are integration constants.

By substituting equation (33) or (34) into (26), the transfer matrix function of equation (24) for the $w$ th pile slice of the $i$ th pile segment can be expressed as

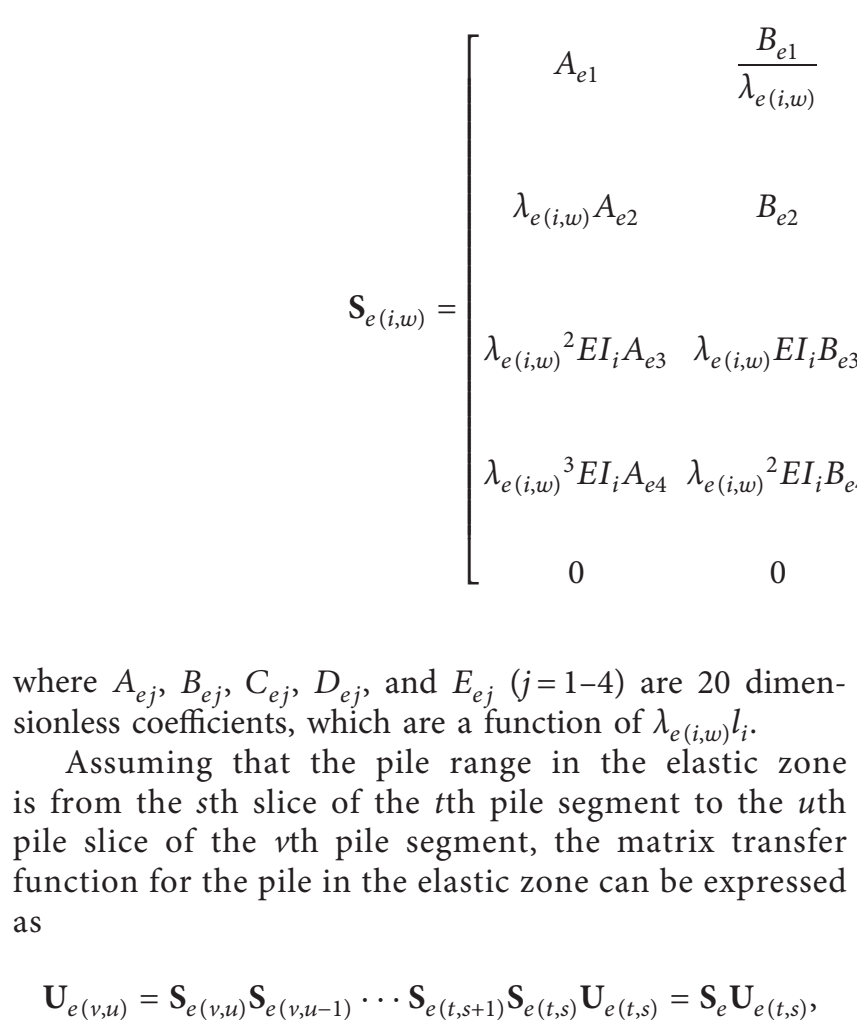

where $\mathbf{U}_{e(i, w)}=\left[y_{e(i, w)}, \varphi_{e(i, w)}, M_{e(i, w)}, V_{e(i, w)}, 1\right]^{T} ; \mathbf{U}_{e(i, w-1)}=$ $\left[y_{e(i, w-1)}, \varphi_{e(i, w-1)}, M_{e(i, w-1)}, V_{e(i, w-1)}, 1\right]^{T}$.

$\mathbf{S}_{e(i, w)}$ is the transfer matrix coefficient of the $w$ th pile slice of the $i$ th pile segment when the pile section is in the elastic zone: where $\mathbf{S}_{e}$ is the overall transfer matrix coefficient of the pile in the elastic zone. as

where $\mathbf{U}_{\left(n, n_{n}\right)}=\left[y_{\left(n, n_{n}\right)}, \varphi_{\left(n, n_{n}\right)}, M_{\left(n, n_{n}\right)}, V_{\left(n, n_{n}\right)}, 1\right]^{T}$ and $\mathbf{U}_{0}=$ $\left[y_{0}, \varphi_{0}, M_{0}, V_{0}, 1\right]^{T}$ are pile deflection vectors, slope, bending moment, and shear force for the pile tip and pile head, respectively. $\mathbf{S}_{(i, w)}$ is the transfer matrix coefficient, which is calculated by equations (31) and (36) for piles in the 


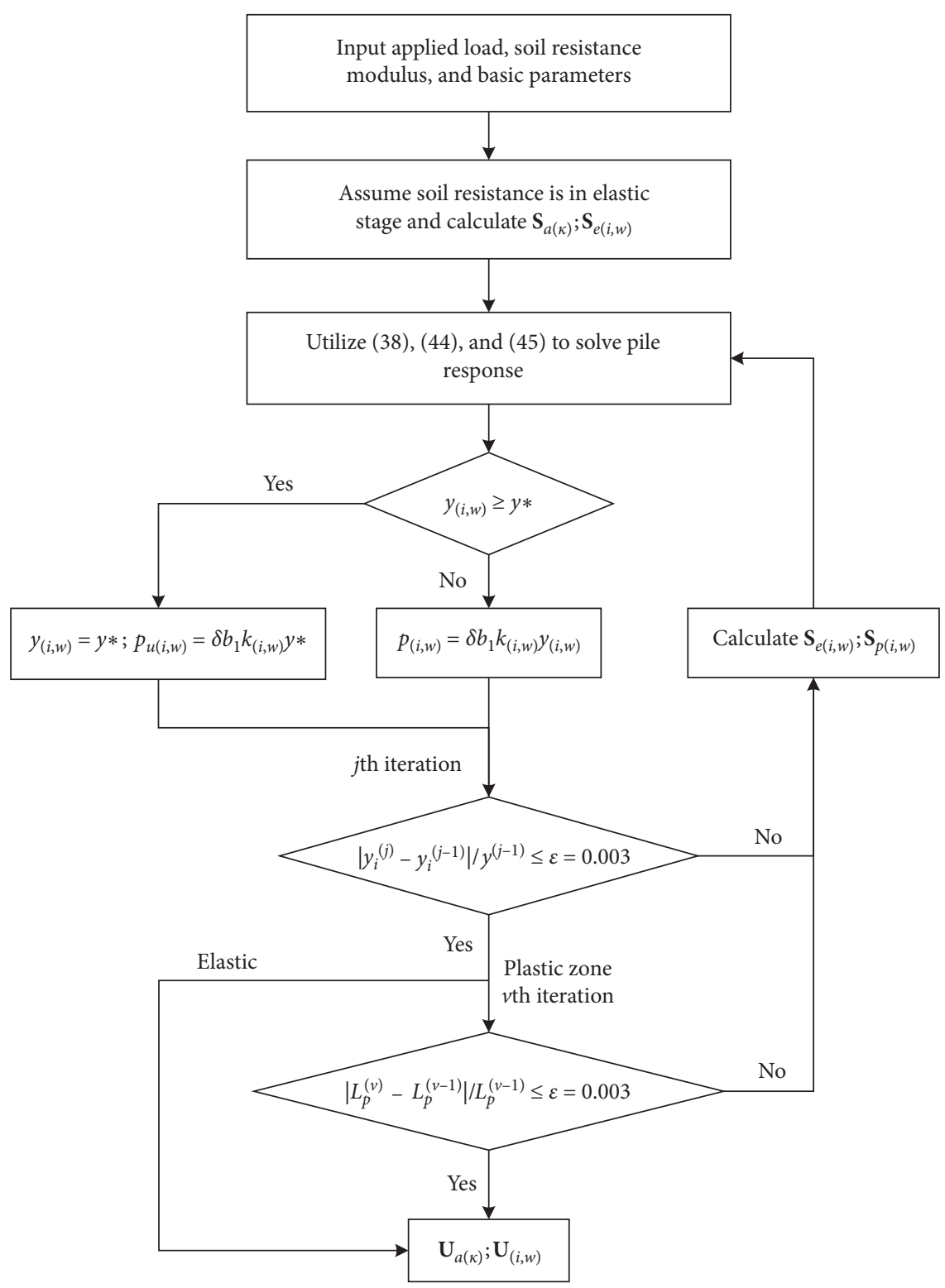

Figure 4: Algorithm to estimate the response of passively loads piles adjacent to a surcharge load.

plastic zone and elastic zone, respectively. $\mathbf{S}_{a}$ is the overall transfer matrix coefficient of the pile in the free zone as deduced in equation (29). $\mathbf{S}$ is defined as the overall pile transfer matrix coefficient, which is the product of the transfer matrix coefficient of each pile slice in the sequence from pile head to pile toe.

Equation (38) is composed of four equations with eight variables including the pile deflection, slope, bending moment, and shear force at the pile head and pile toe. The boundary conditions at the pile head and pile toe must be specified to solve this equation. Five types of boundary conditions are considered in this study: free-head, slip-head, fixed-head, free-base, and fixed-base.

For the free-head case, the boundary conditions at the pile head are

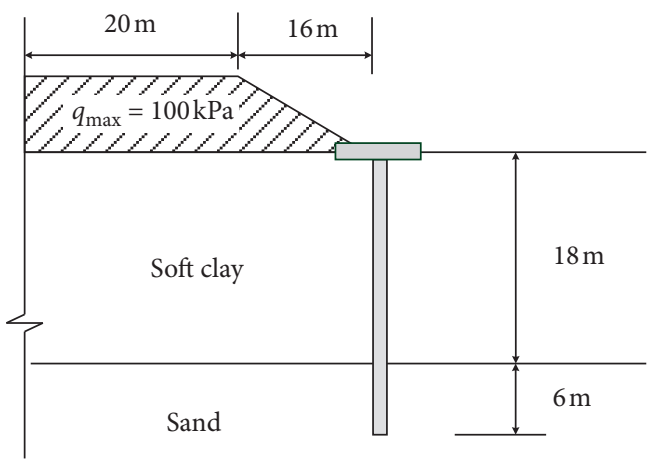

Figure 5: Calculation case [9]. 


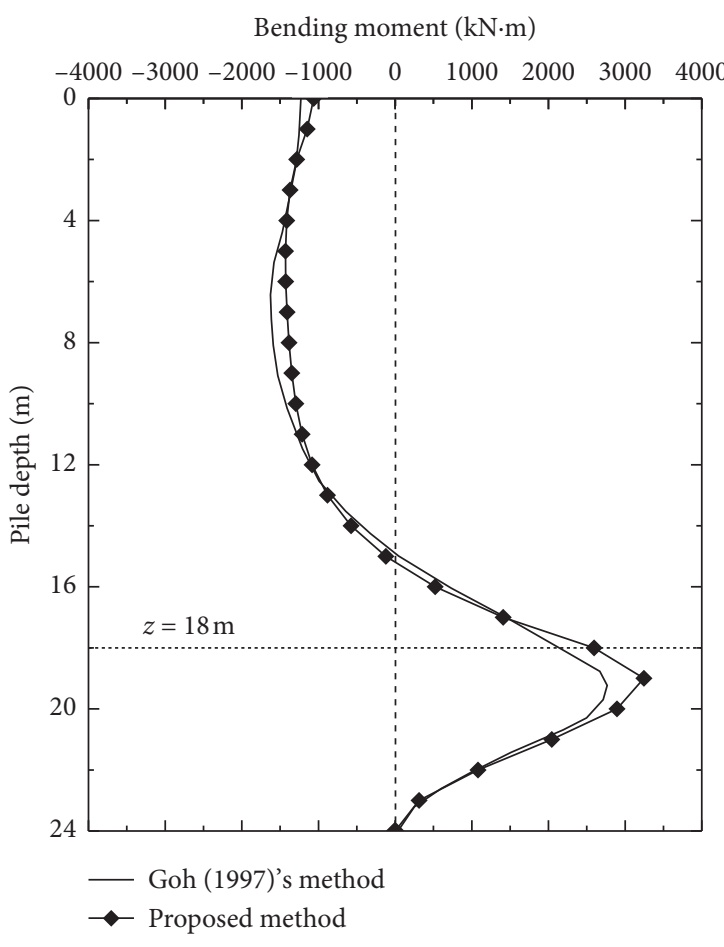

(a)

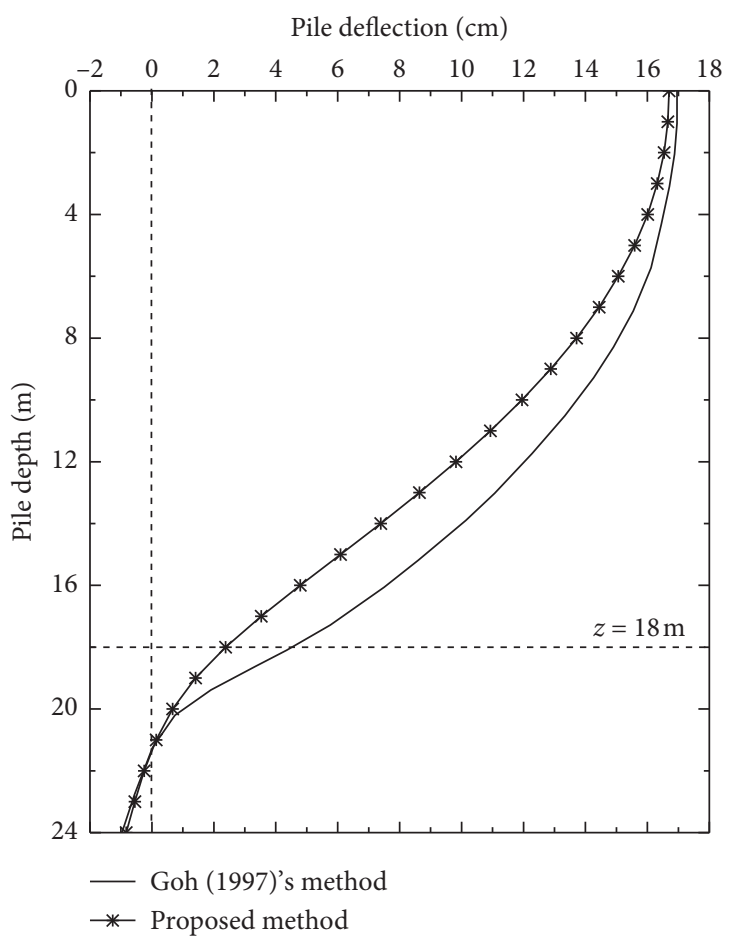

(b)

Figure 6: Comparison of bending moment and pile deflection. (a) Bending moment. (b) Pile deflection.

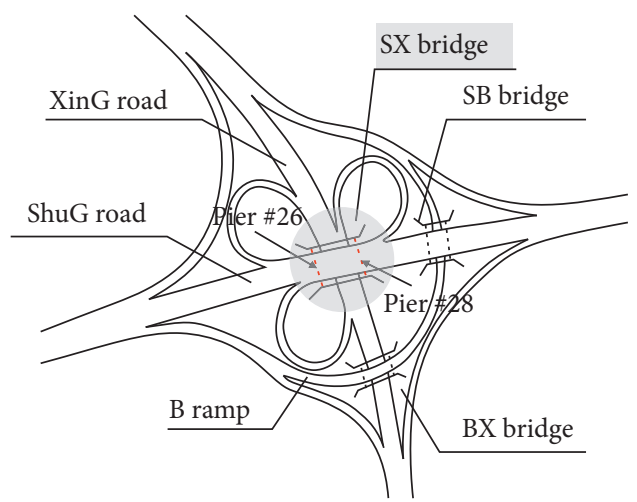

(a)

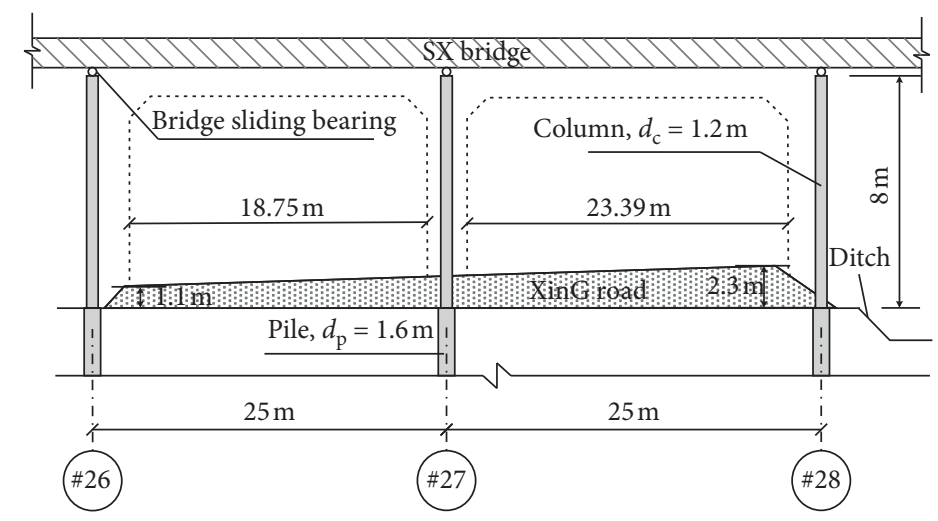

(b)

FIgURE 7: Diagram of the SX Bridge. (a) Plane location of SX Bridge. (b) Sectional view of SX Bridge.

$$
\begin{gathered}
M_{0}=M_{t} ; \\
V_{0}=Q_{t} .
\end{gathered}
$$

For the slip-head case, the boundary conditions at the pile head are

$$
\begin{gathered}
\varphi_{0}=0 ; \\
V_{0}=Q_{t} .
\end{gathered}
$$

For the fixed-head case, the boundary conditions at the pile head are

$$
\begin{aligned}
& y_{0}=0 ; \\
& \varphi_{0}=0 .
\end{aligned}
$$

For the free-base case, the boundary conditions at the pile head are

$$
\begin{gathered}
M_{\left(n, n_{n}\right)}=0 ; \\
V_{\left(n, n_{n}\right)}=0 .
\end{gathered}
$$

For the fixed-base case, the boundary conditions at the pile head are 


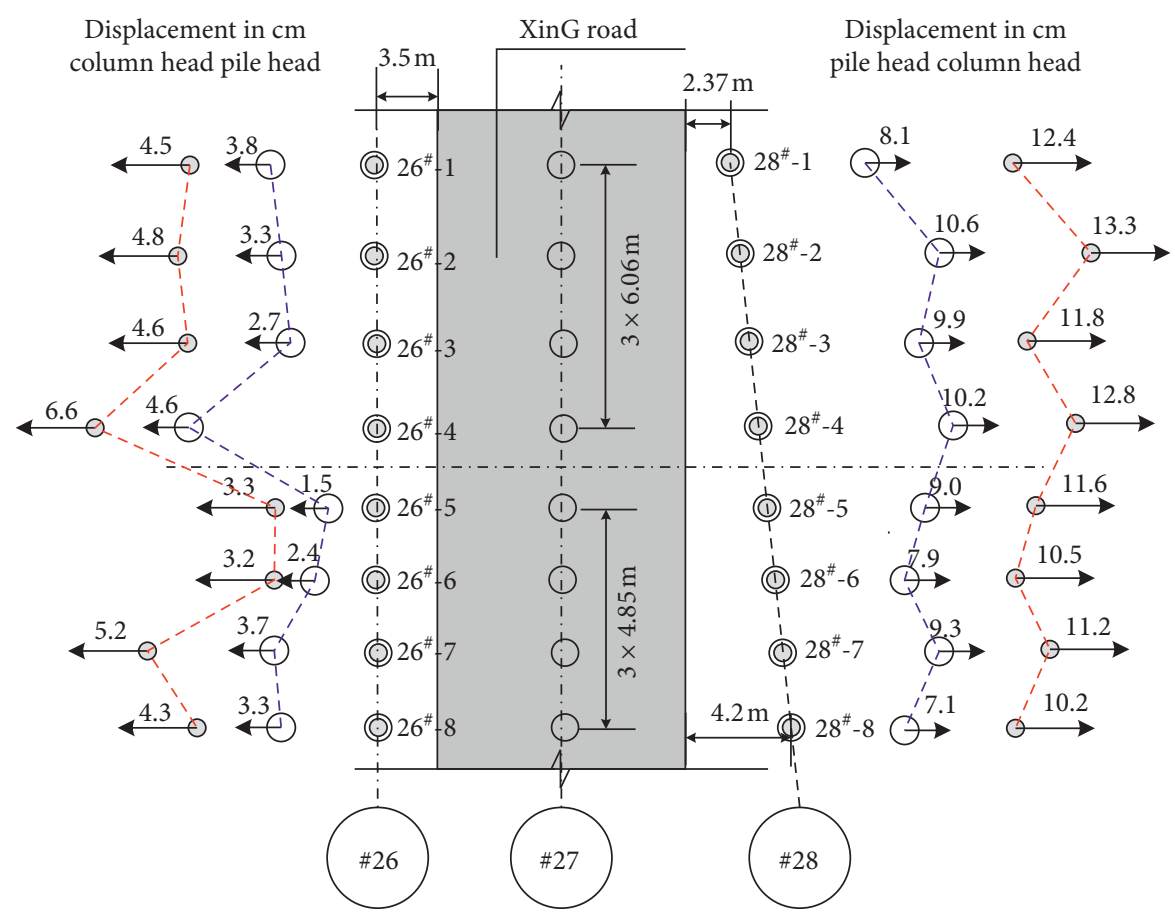

FIgURE 8: Displacement of columns of SX Bridge (schematic).

TABLe 1: Physical and mechanical properties of the soils at the interchange site.

\begin{tabular}{lccccccccc}
\hline Layer & Thickness/m & $\begin{array}{c}\text { Moisture } \\
\text { content, } w / \%\end{array}$ & $\begin{array}{c}\text { Unit weight, } \\
\gamma / \mathrm{kNm}^{-3}\end{array}$ & $\begin{array}{c}\text { Void } \\
\text { ratio, } e\end{array}$ & $\begin{array}{c}\text { Plasticity } \\
\text { index, } I_{P}\end{array}$ & $\begin{array}{c}\text { Liquidity } \\
\text { index, } I_{L}\end{array}$ & $\begin{array}{c}\text { Cohesion, } \\
c / \mathrm{kPa}\end{array}$ & $\begin{array}{c}\text { Friction angle, Soil modulus, } \\
\varphi / \text { degrees } \\
E_{s 1-2} / \mathrm{MPa}\end{array}$ \\
\hline 1. Clay & $1.7 \sim 2.5$ & 40.1 & 1.79 & 1.143 & 25.2 & 0.57 & 22.9 & 7.2 & 3.43 \\
2. Mud & $15.5 \sim 22.0$ & 69.2 & 1.57 & 1.946 & 31.9 & 1.23 & 8.7 & 2.0 & 1.52 \\
clay & & & 1.92 & 0.842 & 15.1 & 0.37 & 39.4 & 12.9 & 5.82 \\
3. Clay & $1.5 \sim 14.0$ & 29.2 & 2.04 & 0.582 & & & 30.1 & 20.2 & 8.04 \\
4. Sand & $0.8 \sim 4.2$ & 18.9 & 1.99 & 0.703 & 15.1 & 0.22 & 43.2 & 17.8 & 5.40 \\
5. Clay & $1.0 \sim 18.5$ & 23.9 & 2.02 & 0.581 & & & 29.0 & 20.1 & 5.84 \\
6. Sand & $0.0 \sim 4.5$ & 17.1 & 2.00 & 0.659 & 14.2 & 0.20 & 45.2 & 19.8 \\
7. Clay & Unpenetrated & 20.4 & & & & & & 7.97 \\
\hline
\end{tabular}

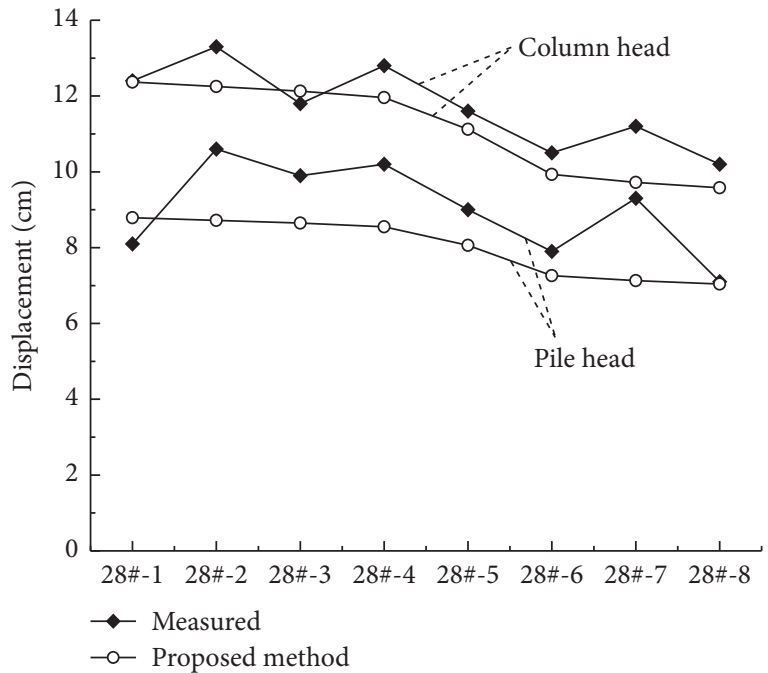

(a)

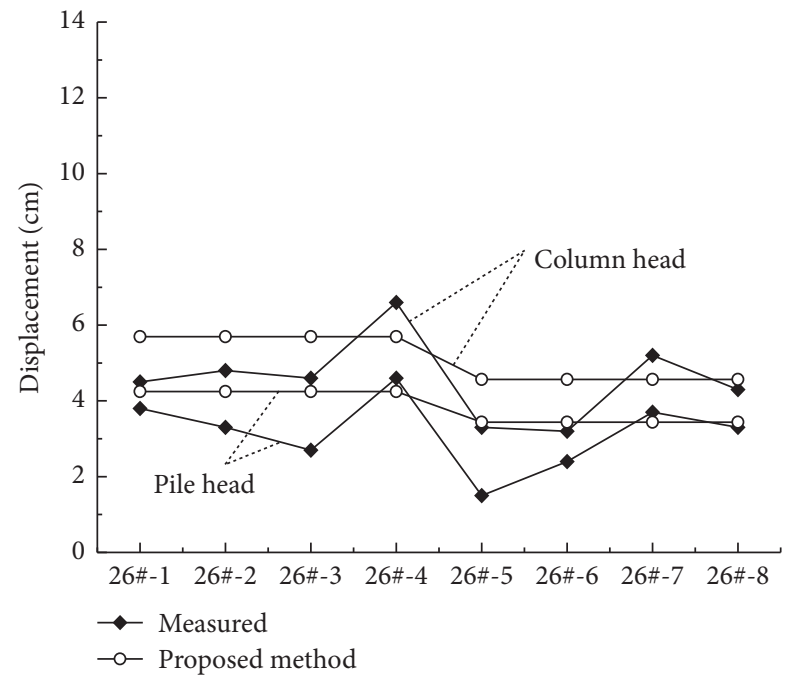

(b)

Figure 9: Measured and computed displacement. (a) \#28 piers. (b) \#26 piers. 


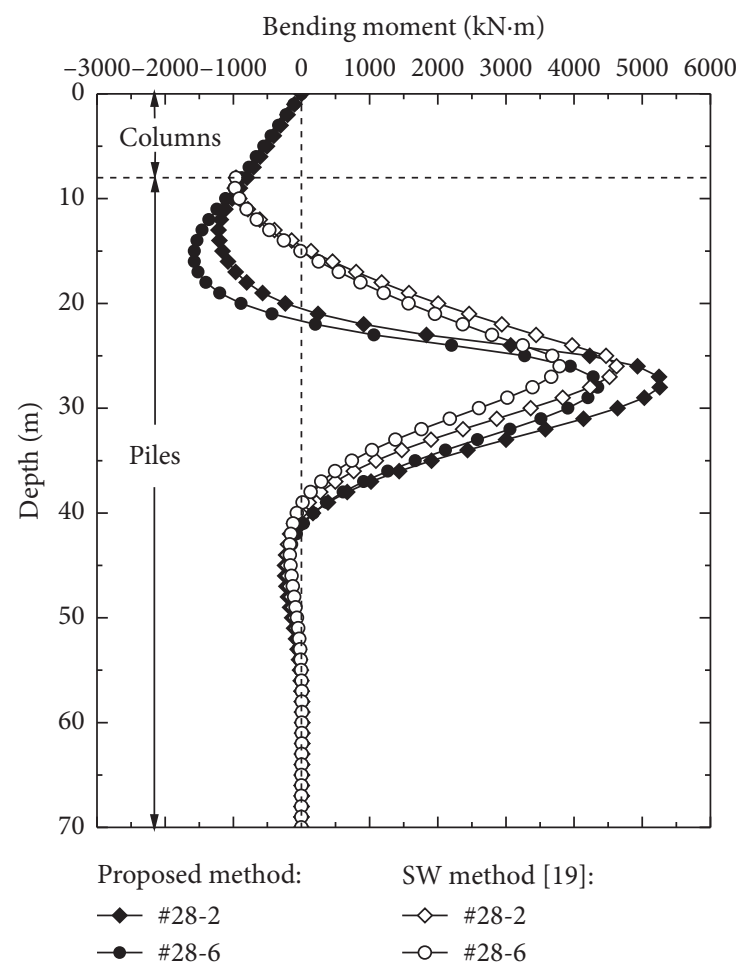

Figure 10: Computed bending moment of columns and piles.

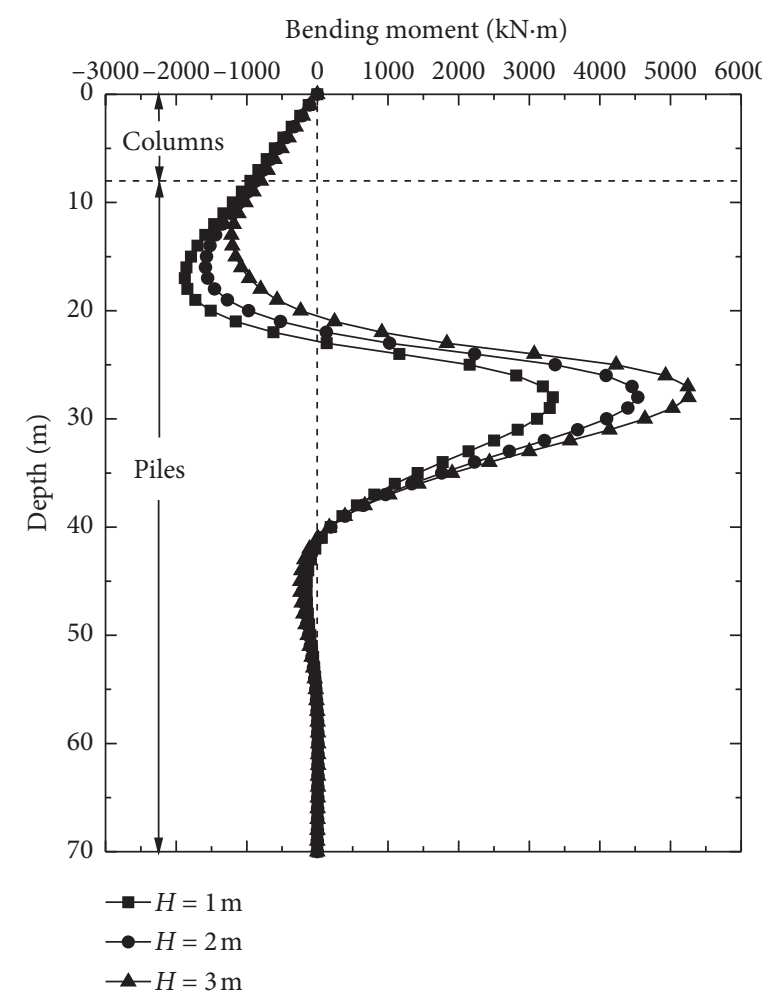

(a)

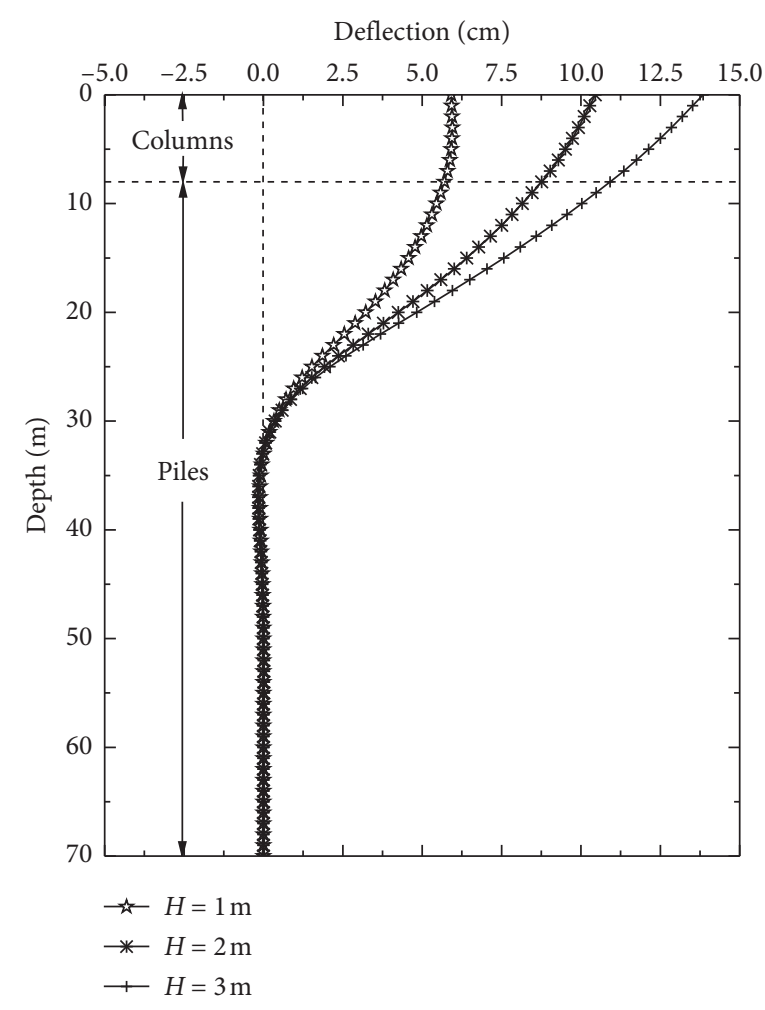

(b)

Figure 11: Effect of $\mathrm{H}$ on the piles-columns response. (a) Bending moment. (b) Deflection. 


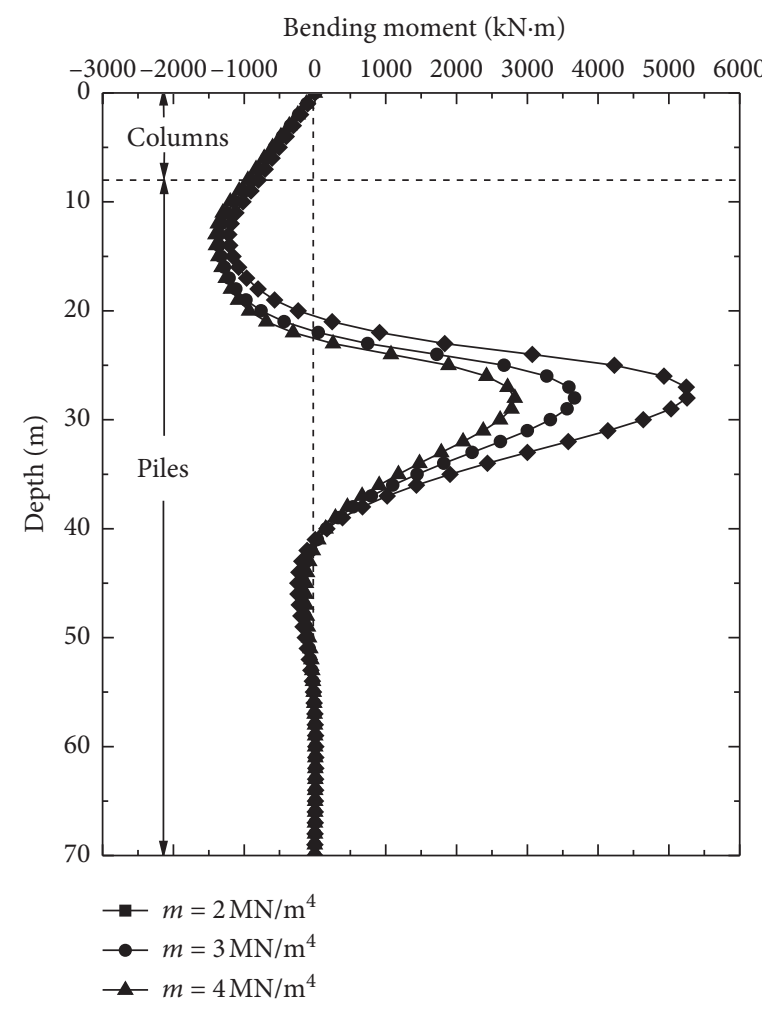

(a)

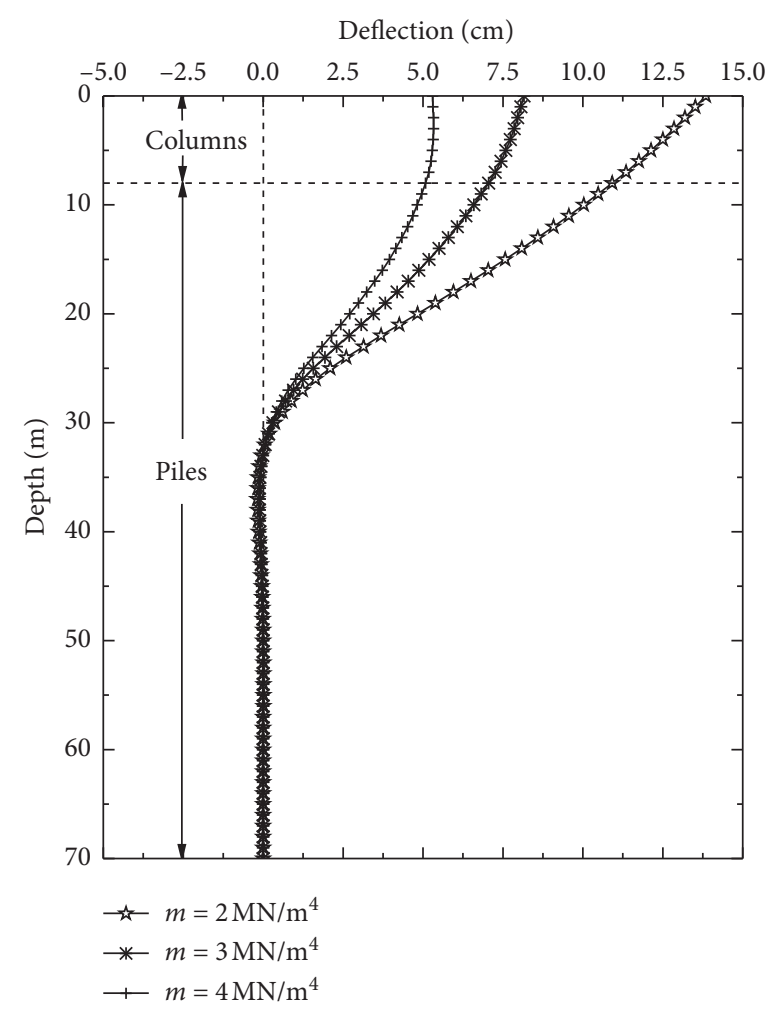

(b)

FIGURE 12: Effect of soil resistance on the piles-columns response. (a) Bending moment. (b) Deflection.

$$
\begin{aligned}
& y_{\left(n, n_{n}\right)}=0 ; \\
& \varphi_{\left(n, n_{n}\right)}=0 .
\end{aligned}
$$

Substituting one of the pile head boundary conditions and one of the pile base boundary conditions into equation (38), the remaining pile head variables can be calculated. Thus, based on the response of the pile head $\mathbf{U}_{0}$, the solution for the pile in the free zone at any depth can be calculated by

$$
\mathbf{U}_{a(\kappa)}=\mathbf{S}_{a(\kappa)} \mathbf{S}_{a(\kappa-1)} \cdots \mathbf{S}_{a(2)} \mathbf{S}_{a(1)} \mathbf{U}_{0} .
$$

Similarly, the pile response at any depth beneath the ground surface can be calculated by

$$
\mathbf{U}_{(i, w)}=\mathbf{S}_{(i, w)} \mathbf{S}_{(i, w-1)} \cdots \mathbf{S}_{(i-1,1)} \mathbf{S}_{(i-1, w-1)} \cdots \mathbf{S}_{(1,2)} \mathbf{S}_{(1,1)} \mathbf{S}_{a} \mathbf{U}_{0}
$$

The algorithm for calculating $\mathbf{U}_{a(\kappa)}$ and $\mathbf{U}_{(i, w)}$ is summarized in Figure 4, in which the pile deflection convergence criteria $\varepsilon=0.003$ of the $(j-1)$ th and $j$ th iteration guarantee iteration accuracy.

\section{Validation}

In this section, the proposed analytical method is validated by analyzing two cases, one from existing literature and a new case.

3.1. Case from [9]. Based on the displacement-based method, a simplified numerical procedure for analyzing the pile response to lateral soil displacement was described in [9], in which free-field displacements were directly used to solve for the soil-pile load transfer mechanism. This method was applied and verified using several full-scale and centrifuge model tests. Figure 5 shows the calculation model [9], in which the pile embedded in layered clay-sand was analyzed. Clay and sand physical properties were summarized in [9]. The pile was assumed to have been installed prior to construction of the embankment and was connected to a rigid cap such that the pile head could be deflected without rotating $\left(\varphi_{\mathrm{c} 0}=0^{\circ} ; V_{\mathrm{c} 0}=0 \mathrm{kN}\right)$. The pile has a length of $L=24 \mathrm{~m}$, diameter $d=1.0 \mathrm{~m}$, spacing $s=2.0 \mathrm{~m}$, and modulus $E=28 \mathrm{GPa}$. The soil resistance was assumed to increase linearly with depth $\left(n=1 ; z_{0}=4.5 \mathrm{~m}\right)$, and the coefficients of the soil reaction modulus $\left(m=2 \mathrm{MN} / \mathrm{m}^{4}\right.$ for clay and $30 \mathrm{MN} / \mathrm{m}^{4}$ for the sand) were evaluated using Skempton's empirical method [36].

Figure 6 shows the bending moment and pile deflection predicted by the numerical results [9] and the proposed method. The variation of bending moment and pile deflection with pile depth by the two methods agreed well. There is an underprediction of the pile deflection of the proposed method in comparison to the numerical results [9]. The discrepancy may be because of the different soil models used by the two methods. The pile-soil interaction was modeled by hyperbolic soil springs and the soil resistance was assumed constant with depth in [9], while elasticperfectly plastic soil model was used and the soil resistance was assumed to increase linearly with depth in this paper. 


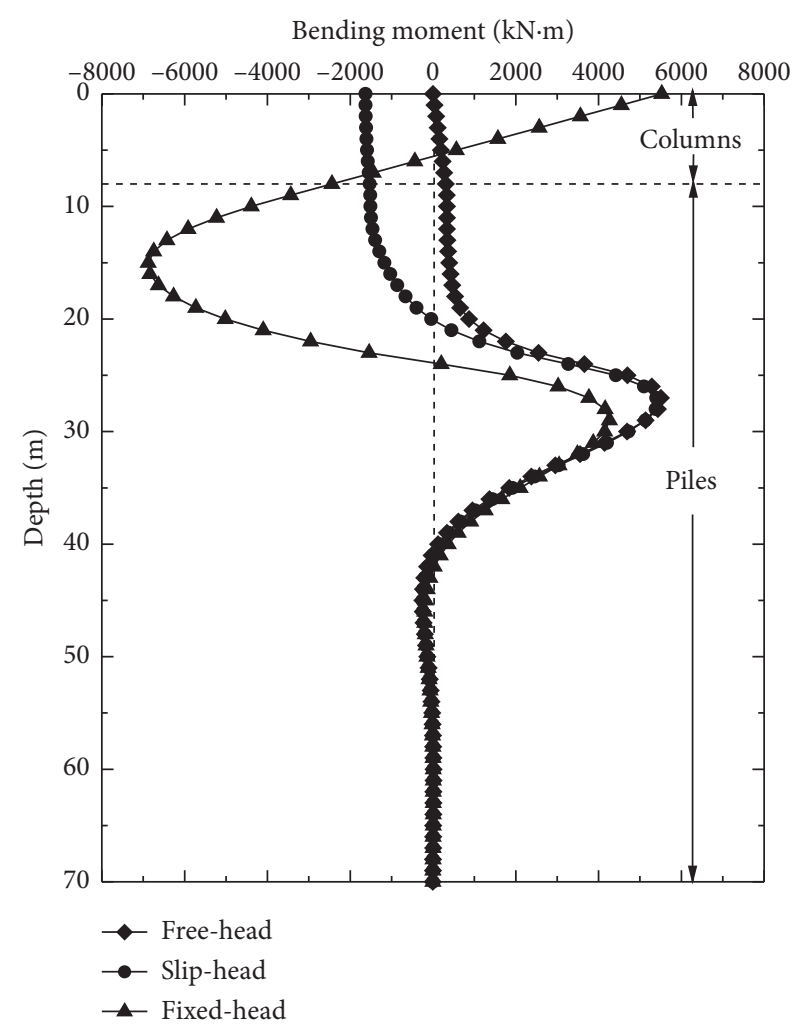

(a)

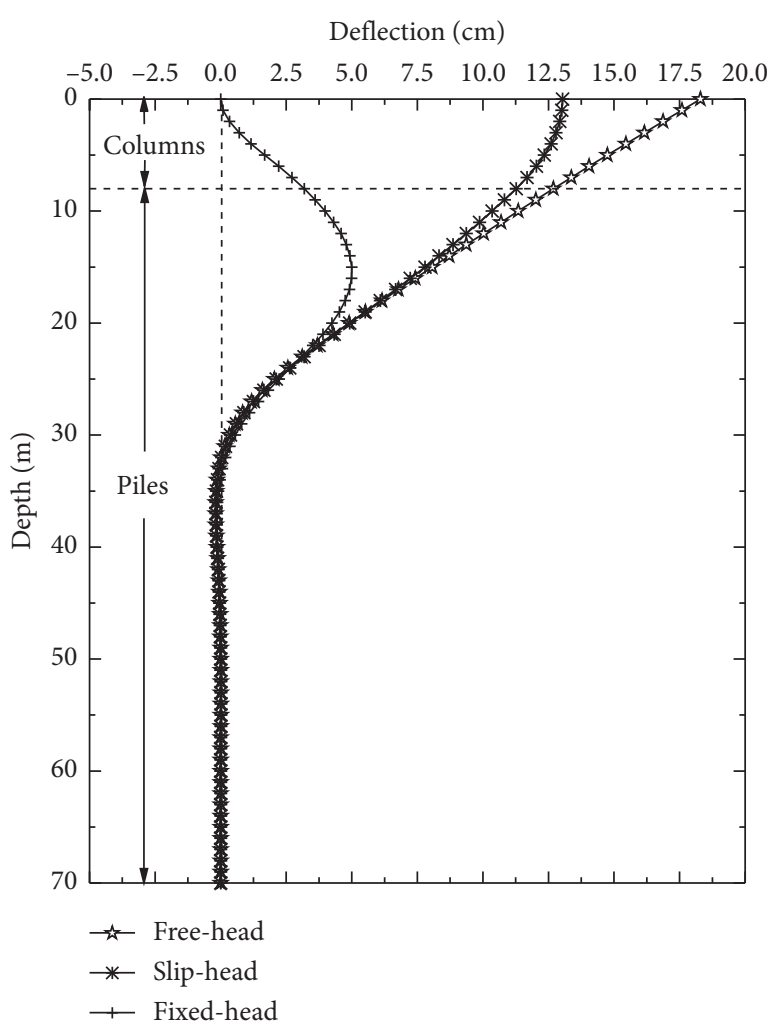

(b)

FIGURE 13: Effect of boundary conditions on the piles-columns response. (a) Bending moment. (b) Deflection.

The soil resistance of the proposed method is larger than [9] under $9 \mathrm{~m}$, which result in smaller pile deflection of the proposed method.

3.2. Bridge Pile Foundation near an Embankment. The method described above is also employed to analyze the response of offset piles columns in the SX Bridge at Lianyungang, China. SX Bridge is one of the three bridges of the XinG Road interchange, a semicloverleaf semidirectional compounded interchange (Figure 7(a)). XinG Road passes beneath the SX Bridge between the $\# 26$ and $\# 28$ piers (Figure 7(b)). XinG Road has a width of $42 \mathrm{~m}$ and a slope of $3 \%$. The road shoulder height adjacent to the \#26 pier is $1.1 \mathrm{~m}$, and the road shoulder height adjacent to the \#28 pier is $2.3 \mathrm{~m}$. The \#26 and \#28 piers are all composed of 8 sets of piles columns. The length and diameter of piles are $62 \mathrm{~m}$ and $1.6 \mathrm{~m}$, respectively. The length and diameter of columns are $8 \mathrm{~m}$ and

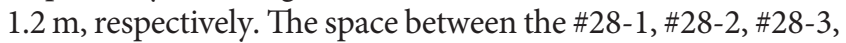
and \#28-4 piles and the space between the \#26-1, \#26-2, \#26-3, and $\# 26-4$ piles are all $6.06 \mathrm{~m}$. The space between the \#28-5, $\# 28-6$, \#28-7, and \#28-8 piles and the space between the \#26-5, $\# 26-6$, \#26-7, and \#26-8 are all 4.85 $\mathrm{m}$. The distance from the \#26 pier (\#26-1 \#26-8) to the XinG Road slope is $3.5 \mathrm{~m}$. The distance from the \#28 piers to the XinG Road slope increased from $2.37 \mathrm{~m}$ at $\# 28-1$ to $4.20 \mathrm{~m}$ at $\# 28-8$ (Figure 8 ).

The 16 columns of \#26 and \#28 piers were offset away from the embankment after the filling of the XinG was completed. The lateral displacement of column heads in the \#26 pier range from 3.2 to $6.6 \mathrm{~cm}$ and the lateral displacement of column heads in the \#28 piers are all greater than $10.0 \mathrm{~cm}$. The maximum lateral displacement is approximately $13.3 \mathrm{~cm}$ located at the head of the 2 th column of the \#28 pier (Figure 8).

The average XinG Road embankment height is $1.7 \mathrm{~m}$; however, due to the presence of a $1.0 \mathrm{~m}-1.5 \mathrm{~m}$ side trench outside the \#28 pier, the effective embankment height in the calculation is $3.0 \mathrm{~m}$. The embankment fill unit weight is $17 \mathrm{kN} / \mathrm{m}^{3}$. Soil mechanical indicators are based on the data from the investigation site and associated triaxial tests (Table 1). The soft soil resistance coefficient is recommended as $0.55 \mathrm{MN} / \mathrm{m}^{4}$ based on the resistance coefficient reference value of the rock and soil provided by CRSSDIG [37]. In addition, sliding rubber bearings are used on the top of the columns, and the forces on the column heads are $N_{0}=5379 \mathrm{kN}, M_{0}=0 \mathrm{kN} \cdot \mathrm{m}$, and $V_{0}=120 \mathrm{kN}$. The piles and columns are all composed of reinforce concrete, with a unit weight and modulus of $25 \mathrm{kN} / \mathrm{m}^{3}$ and $28.5 \mathrm{GPa}$, respectively.

Figure 9 shows the calculated column and pile lateral displacement compared to the measured data. It is noted that the calculated results of \#28 piers are mainly smaller than the measured results, while the calculated results of \#26 piers are mainly larger than the measured results. The reason is that the average embankment height is used in the proposed method, which is lower than the actual height at \#28 piers and higher than the actual heights at \#26 piers 


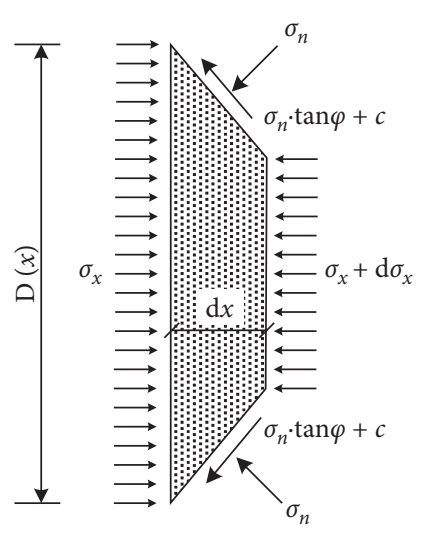

(a)

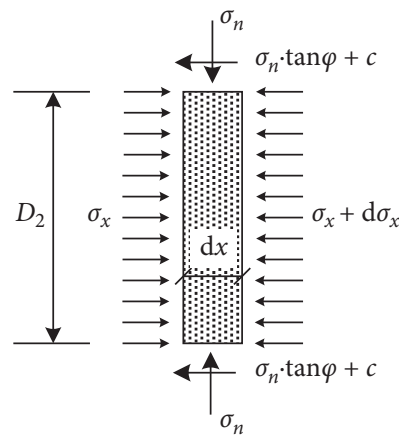

(b)

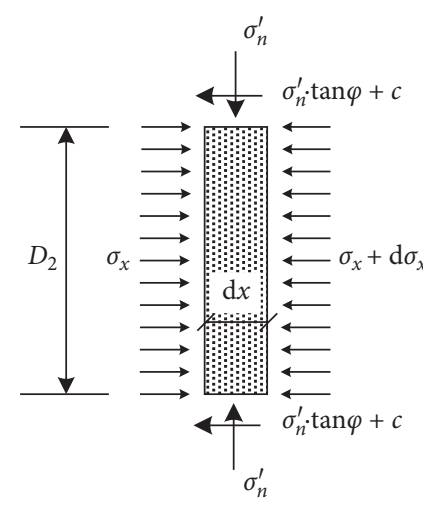

(c)

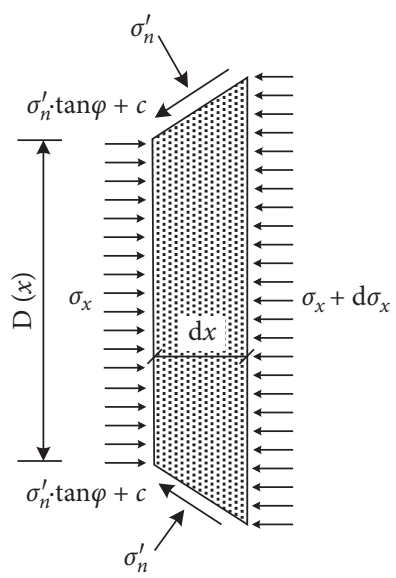

(d)

Figure 14: Small element of plastically deforming soil. (a) $B B^{\prime} E^{\prime} E$ zone. (b) $E E^{\prime} A^{\prime} A$ zone. (c) $E E^{\prime} A^{\prime} A$ zone. (d) $D D^{\prime} G^{\prime} G$ zone.

(Figure 7). Figure 10 shows the calculated bending moment along the column and pile for \#28-2 and \#28-6 from the proposed method and the improved strain wedge (SW) method [19]. The predictions of the improved SW method [19] are obtained from back analysis of measured pile head displacements which reflected real field behavior; however, it does not consider the effect of soil arching between piles and the rotation of pile head. This is the reason for the underprediction of pile bending moment of the improved SW method [19] in comparison to the proposed method.

3.3. Factors Influencing Pile Response. Taking \#28-2 as an example, the effect of embankment pressure, soil resistance, and column boundary conditions on pile-column response is calculated. The influence of embankment pressure on the performance of neighboring piles columns is investigated by varying the embankment height between $1.0 \mathrm{~m}, 2.0 \mathrm{~m}$, and $3.0 \mathrm{~m}$. The other parameters are held constant as in previous sections. Increasing embankment height (or embankment pressure) causes an increase in bending moment and deflection of neighboring piles columns (Figure 11). The maximum pile bending moment increased from $3333.7 \mathrm{kN} \cdot \mathrm{m}$ for $H=1.0 \mathrm{~m}$ to $5254.8 \mathrm{kN} \cdot \mathrm{m}$ for $H=3.0 \mathrm{~m}$, a $57.6 \%$ increase. The column head displacement varied from $5.92 \mathrm{~cm}$ for $H=1.0 \mathrm{~m}$ to $13.85 \mathrm{~cm}$ for $H=3.0 \mathrm{~m}$, an increase of 1.34 times. With increasing embankment height (or embankment pressure), more passive loads are transferred from moving soil to the piles, and the surcharge loading of the soft soil has a significant impact on nearby piles.

The influence of soil resistance on pile-column performance is investigated by varying the mud clay reaction modulus coefficient between $2 \mathrm{MN} / \mathrm{m}^{4}, 3 \mathrm{MN} / \mathrm{m}^{4}$, and $4 \mathrm{MN} / \mathrm{m}^{4}$. Figure 12 shows the effect of the clay reaction modulus coefficient on pile-column response. With increasing clay reaction modulus coefficient, the pile-column bending moment and deflection decrease significantly (Figure 12). The maximum pile bending moment and column head displacement are reduced by $30.2 \%$ and $40.8 \%$ from $m=2 \mathrm{MN} / \mathrm{m}^{4}$ to $m=3 \mathrm{MN} / \mathrm{m}^{4}$. The reductions increase to $46.2 \%$ and $61.7 \%$ for $m=4 \mathrm{MN} / \mathrm{m}^{4}$. These results clearly show that soil resistance has a significant impact on pile response; hence, the geological conditions around the piles should be carefully investigated, and reinforcement or protective measures should be employed in soft soils to ensure the stability and safety of piles adjacent to the embankment.

The influence of boundary conditions is investigated by comparing the free-head case $\left(M_{\mathrm{c} 0}=0, V_{\mathrm{c} 0}=0\right)$, slip-head case $\left(\varphi_{\mathrm{c} 0}=0, V_{\mathrm{c} 0}=0\right)$, and fixed-head case $\left(y_{\mathrm{c} 0}=0, \varphi_{\mathrm{c} 0}=0\right)$. Figure 13 shows the effect of boundary conditions on the piles-columns responses. Bending moment and deflection along the pile and column for the fixed-head case are significantly different from the other two cases. By comparing this case to the free-head and slip-head cases, there is a negative moment in the upper part of the pile, and the maximum pile displacement occurs at $1 / 2$ of the soft clay thickness. Comparing the free-head and slip-head cases, the difference in bending moment primarily occurs in the upper $2 / 3 \mathrm{~s}$ of the soft clay, and the difference in pile deflection primarily occurs within $7 d$ depth beneath the pile head.

\section{Conclusions}

Based on plastic deformation theory, a load transfer model was presented to analyze the soil-pile interaction of passive piles adjacent to a surcharge load. A semianalytical solution was developed to assess the response of piles under active and passive loads using the transfer matrix approach.

The proposed method was validated against the displacement-based method proposed by Goh et al. [9] and field measurements at SX Bridge, Lianyungang, China. Results showed that the proposed method can provide good response predictions (i.e., deflection, bending moment, and shear forces) for piles adjacent to a surcharge load.

A parametric study was conducted to investigate the influence of the neighboring surcharge pressure, soil resistance, and boundary conditions of pile/column heads on piles adjacent to a surcharge load. Results indicate that the maximum bending moment and deflection along piles 
increase with increasing neighboring surcharge pressure and decreasing soil resistance. The boundary conditions of pile/ column heads have a significant influence of the response of piles/columns.

\section{Notations}

$A_{a j}, A_{p j}, A_{e j}:$
$A_{\mathrm{p}}:$
$B_{a j}, B_{p j}, B_{e j}:$
$c:$
$C_{a j}, C_{p j}, C_{e j}:$
$d:$
$D_{1}:$
$D_{2}:$
$D_{a j}, D_{p j}, D_{e j}:$
$E I:$
$E_{a j}, E_{p j}, E_{e j}:$
$k:$
$\bar{k}_{(i, w)}:$

Calculation coefficients

Cross-sectional area of the pile

Calculation coefficients

Cohesion of the soil

Calculation coefficients

Pile diameter

Pile spacing

Net spacing between piles

Calculation coefficients

Bending stiffness; the pile has length

Calculation coefficients

Reaction modulus of soil mass

Average value of soil reaction behind the pile in the $w$ th pile slice of the ith pile segment below the ground

$K_{0}$ : Coefficient of the static Earth pressure

$L: \quad$ Pile length

$L_{a}$ : $\quad$ Pile length above the ground surface

$L_{b}$ : $\quad$ Pile length below the ground surface

$l_{a}$ : $\quad$ Length of each pile slice in free zone

$M_{0}$ : $\quad$ Moment acting on the pile head

$M_{a(\kappa)}$, Moment for pile in the free zone, plastic

$M_{p(i, w)}, M_{e(i, w)}$ : zone, and elastic zone

$N_{0}$ : Axial load acting on the pile head

$\bar{N}_{a(\kappa)}$ : $\quad$ Average axial force of the $\kappa$ th slice in free

$\bar{N}_{(i, w)}$ zone

Average axial force for the pile in $w$ th pile slice of the $i$ th pile segment below the ground

\begin{tabular}{|c|c|}
\hline$p:$ & Soil resistance \\
\hline$p_{u}:$ & Ultimate soil resistance \\
\hline$\overline{p_{u}(i, w)}$ & $\begin{array}{l}\text { Average value of ultimate soil resistance } \\
\text { for the pile in the } w \text { th pile slice of the } i \text { th } \\
\text { pile segment }\end{array}$ \\
\hline$P_{0}:$ & Static Earth pressure \\
\hline$P_{s}(z):$ & $\begin{array}{l}\text { Distributed passive load acting on the pile } \\
\text { below ground surface }\end{array}$ \\
\hline${\overline{P_{s}}}_{(i, w)}:$ & $\begin{array}{l}\text { Average value of passive load acting on the } \\
\text { pile in the } w \text { th pile slice of the ith pile } \\
\text { segment }\end{array}$ \\
\hline $\bar{q}_{a(\kappa)}:$ & $\begin{array}{l}\text { Average distributed force acting on the } \kappa \text { th } \\
\text { pile slice in free zone }\end{array}$ \\
\hline S: & $\begin{array}{l}\text { Overall transfer matrix coefficient of the } \\
\text { entire pile }\end{array}$ \\
\hline $\mathbf{S}_{a}:$ & $\begin{array}{l}\text { Overall transfer matrix coefficient of the } \\
\text { pile in the free zone }\end{array}$ \\
\hline $\mathbf{S}_{a(\kappa)}$ & $\begin{array}{l}\text { Transfer matrix coefficient of the } \kappa \text { th pile } \\
\text { slice in the free zone }\end{array}$ \\
\hline $\mathbf{S}_{p}:$ & $\begin{array}{l}\text { Overall transfer matrix coefficient of the } \\
\text { pile in the plastic zone }\end{array}$ \\
\hline
\end{tabular}

$\mathbf{S}_{p(i, w)}$ :

$\mathbf{S}_{e}$ :

$\mathbf{S}_{e(i, w)}$ :

$\mathbf{U}_{a(\kappa)}, \mathbf{U}_{p(i, w)}$,

$\mathbf{U}_{e(i, w)}$ :

$V_{0}$ :

$V_{a(\kappa)}, V_{p(i, w)}$,

$V_{e(i, w)}$ :

$y$ :

$y_{a(\kappa)}, y_{p(i, w)}$,

$y_{e(i, w)}$ :

$z$ :

$z_{a(\kappa)}$,

$z_{p(i, w)}, z_{e(i, w)}:$

$\gamma, \gamma_{\mathrm{p}}$ :

$\varphi$ :

$\varphi_{a(\kappa)}, \varphi_{p(i, w)}$,

$\varphi_{e(i, w)}$ :

$\lambda_{a(\kappa)}, \lambda_{p(i, w)}$,

$\lambda_{e(i, w)}$ :

$\eta$ :

$\delta:$

\section{Appendix}

\section{A. Lateral Stress in Soils Surrounding Piles}

The equilibrium of forces acting on a small soil element in zones $B B^{\prime} E^{\prime} E, E E^{\prime} A^{\prime} A, A A^{\prime} D^{\prime} D$, and $D D^{\prime} G^{\prime} G$ is, respectively, considered in the $x$-direction (Figure 14).

In the $B B^{\prime} E^{\prime} E$ zone,

$$
\begin{aligned}
& D_{\mathrm{I}}(x) \sigma_{x}-2 \sigma_{n} N_{\varphi}^{1 / 2} \mathrm{~d} x-2 \tau_{n} \mathrm{~d} x \\
& \quad=\left(\sigma_{x}+\mathrm{d} \sigma_{x}\right)\left[D_{\mathrm{I}}(x)-2 \mathrm{~d} x \cdot \tan \left(\frac{\pi}{4}+\frac{\varphi}{2}\right)\right] .
\end{aligned}
$$

In the $E E^{\prime} A^{\prime} A$ zone,

$$
D_{2} \sigma_{x}-2 \tau_{n} \mathrm{~d} x=\left(\sigma_{x}+\mathrm{d} \sigma_{x}\right) D_{2}
$$

In the $A A^{\prime} D^{\prime} D$ zone,

$$
D_{2} \sigma_{x}-2 \tau_{n}^{\prime} \mathrm{d} x=\left(\sigma_{x}+\mathrm{d} \sigma_{x}\right) D_{2} .
$$

In the $D D^{\prime} G^{\prime} G$ zone,

$$
\begin{aligned}
& D_{\mathrm{IV}}(x) \sigma_{x}+2 \sigma_{n}^{\prime} N_{\varphi}^{\prime 1 / 2} \mathrm{~d} x-2 \tau_{n}^{\prime} \mathrm{d} x \\
& \quad=\left(\sigma_{x}+\mathrm{d} \sigma_{x}\right)\left[D_{\mathrm{IV}}(x)+2 \mathrm{~d} x \cdot \tan \left(\frac{\pi}{4}-\frac{\varphi}{2}\right)\right],
\end{aligned}
$$

where $\sigma_{n}=\sigma_{x} N_{\varphi}+2 c \cdot N_{\varphi}^{1 / 2} ; \quad \tau_{n}=\sigma_{n} \tan \varphi+c ; \quad N_{\varphi}=\tan ^{2}$ $(\pi / 4+\varphi / 2) ; \quad \sigma_{n}^{\prime}=\sigma_{x} N_{\varphi}^{\prime}-2 c \cdot N_{\varphi}^{\prime 1 / 2} ; \quad N_{\varphi}^{\prime}=\tan ^{2}(\pi / 4-\varphi / 2) ;$ 
$\tau_{n}^{\prime}=\sigma_{n}^{\prime} \tan \varphi+c ; D_{\mathrm{I}}(x)=D_{2}-2[x+(d / 2) \tan ((\pi / 8)+(\varphi / 4))]$ $N_{\varphi}^{1 / 2} ; D_{\mathrm{IV}}(x)=D_{2}+2[x-(d / 2) \tan ((\pi / 8)-(\varphi / 4))] N_{\varphi}^{\prime 1 / 2}$.

Equations (A.1) (A.4) are differential equations with separated variables and can be integrated as follows:

When $\quad-(d / 2) / \cos ((\pi / 4)-(\varphi / 2)) \leq x \leq-(d / 2) \tan$ $((\pi / 8)+(\varphi / 4))$

$\sigma_{x}^{\mathrm{I}}=\frac{C_{\mathrm{I}} \cdot D_{\mathrm{I}}(x)^{\left(N_{\varphi}+N_{\varphi}^{1 / 2} \tan \varphi-1\right)}-c\left(2 N_{\varphi}^{1 / 2}+2 \tan \varphi+N_{\varphi}^{-1 / 2}\right)}{N_{\varphi}+N_{\varphi}^{1 / 2} \tan \varphi-1}$.

When $-(d / 2) \tan ((\pi / 8)+(\varphi / 4)) \leq x \leq 0$,

$\sigma_{x}^{\mathrm{II}}=\frac{C_{\mathrm{II}} \exp \left(-\left(2 N_{\varphi} \tan \varphi / D_{2}\right) x\right)-c \cdot\left(2 N_{\varphi}^{1 / 2} \tan \varphi+1\right)}{N_{\varphi} \tan \varphi}$.

When $0 \leq x \leq(d / 2) \tan ((\pi / 8)-(\varphi / 4))$,

$\sigma_{x}^{\mathrm{III}}=\frac{C_{\mathrm{III}} \exp \left[-\left(2 N_{\varphi}^{\prime} \tan \varphi / D_{2}\right) x\right]+c\left(2 N_{\varphi}^{\prime 1 / 2} \tan \varphi-1\right)}{N_{\varphi}^{\prime} \tan \varphi}$.

When $(d / 2) \tan ((\pi / 8)-(\varphi / 4)) \leq x \leq(d / 2) / \cos ((\pi / 4)-$ $(\varphi / 2))$,

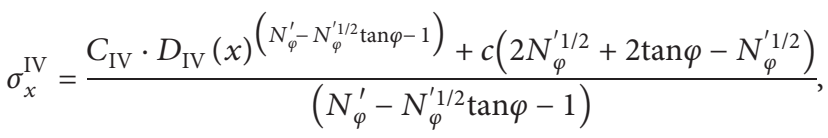

where $C_{\mathrm{I}}, C_{\mathrm{II}}, C_{\mathrm{III}}$, and $C_{\mathrm{IV}}$ are integration constants.

Assuming the additional lateral stress acting on surface $B B^{\prime}$ induced by the surcharge load is $\overline{\sigma_{x}}(z)$ which can be determined from Boussinesq's solution and the Flamant integral solution according to the surcharge load distribution characteristics $[26,32]$, the total soil pressure acting on surface $B B^{\prime}, P_{B B^{\prime}}(z)$, can be obtained using (7).

The constant $C_{\mathrm{I}}$ in (A.5) can be obtained considering $P_{B B^{\prime}}(z)$ (see (7)) as the boundary condition (where $x=-(d / 2) / \cos ((\pi / 4)-(\varphi / 2)))$ :

$$
C_{\mathrm{I}}=\frac{P_{B B^{\prime}}(z) \cdot G_{1}+c \cdot G_{2}}{D_{1}^{G_{1}}} .
$$

Using (A.5) and (A.9), the lateral stress $\sigma_{x}^{\mathrm{I}}$ at any point $x$ in the $B B^{\prime} E^{\prime} E$ can be expressed using (3).

In regard to the $E E^{\prime} A^{\prime} A$ zone, considering (3) for $x=$ $-(d / 2) \tan ((\pi / 8)+(\varphi / 4))$ as the boundary condition (surface $\left.E E^{\prime}\right)$, the constant $C_{\mathrm{II}}$ in (A.6) can be obtained:

$$
C_{\mathrm{II}}=\left(1 / G_{1}\right)\left\{\frac{\left.\left[D_{2} / D_{1}\right]^{G_{1}}\left[G_{1} \cdot P_{B B^{\prime}}(z)+c \cdot G_{2}\right]-c \cdot G_{2}\right\} N_{\varphi} \tan \varphi+c \cdot\left(2 N_{\varphi}^{1 / 2} \tan \varphi+1\right)}{\exp \left[-\left(2 N_{\varphi} \tan \varphi / D_{2}\right)(-(d / 2) \tan ((\pi / 8)+(\varphi / 4)))\right] .}\right.
$$

Using (A.6) and (A.10), the lateral stress $\sigma_{x}^{\mathrm{II}}$ at any point $x$ in $E E^{\prime} A^{\prime} A$ can be expressed using (4).

Substituting $x=0$ into (4), the lateral stress acting on the surface $A A^{\prime}, P_{A A^{\prime}}(z)$, can be obtained from (8).

In regard to the $A A^{\prime} D^{\prime} D$ zone, considering $P_{A A^{\prime}}(z)$ as the boundary condition of the surface $A A^{\prime}$, the constant $C_{\text {III }}$ in (A.7) can be obtained:

$$
C_{\mathrm{III}}=P_{A A^{\prime}}(z) N_{\varphi}^{\prime} \tan \varphi-c\left(2 N_{\varphi}^{\prime 1 / 2} \tan \varphi-1\right) .
$$

Using (A.7) and (A.11), the lateral stress $\sigma_{x}^{\mathrm{III}}$ at any point $x$ in the $A A^{\prime} D^{\prime} D$ can be expressed using (5).

In regard to the $D D^{\prime} G^{\prime} G$ zone, considering (5) for $x=$ $(d / 2) \tan ((\pi / 8)-(\varphi / 4))$ as the boundary condition (surface $\left.D D^{\prime}\right)$, the constant $C_{\mathrm{IV}}$ in (A.8) can be obtained:

$$
\begin{aligned}
C_{\mathrm{IV}}= & \frac{H_{1}\left(P_{A A^{\prime}}(z) N_{\varphi}^{\prime} \tan \varphi-2 c N_{\varphi}^{\prime 1 / 2} \tan \varphi+c\right)}{D_{2}^{H_{1}} N_{\varphi}^{\prime} \tan \varphi \exp \left(H_{3} d / D_{2}\right)} \\
& +\frac{c H_{1}\left(2 N_{\varphi}^{\prime 1 / 2} \tan \varphi-1\right)-c H_{2} N_{\varphi}^{\prime} \tan \varphi}{D_{2}^{H_{1}} N_{\varphi}^{\prime} \tan \varphi}
\end{aligned}
$$

Using (A.8) and (A.12), the lateral stress $\sigma_{x}^{\mathrm{IV}}$ at any point $x$ in the $D D^{\prime} G^{\prime} G$ can be expressed using (6).

\section{Data Availability}

The data used to support the findings of this study are available from the corresponding author upon request.

\section{Conflicts of Interest}

The authors declare that there are no conflicts of interest regarding the publication of this article.

\section{Acknowledgments}

This work wass supported by the National Natural Science Foundation of China (Grant no. 51608490) and the Key Scientific Research Project of Colleges and Universities in Henan Province (Grant no. 16A560009), for which the authors are grateful.

\section{References}

[1] H. G. Poulos, "Ground movements-a hidden source of loading on deep foundations," DFI Journal-The Journal of the Deep Foundations Institute, vol. 1, no. 1, pp. 37-53, 2007.

[2] E. Beer, "The effects of horizontal loads on piles, due to surcharge or seismic effects," in Proceedings of 9th International Conference on Soil Mechanics and Foundation Engineering, Tokyo, Japan, July 1977. 
[3] M. Yang, B. T. Zhu, and F. Q. Chen, "Pilot study on collapse of an industrial building due to adjacent surcharge loads," Chinese Journal of Geotechnical Engineering, vol. 24, no. 4, pp. 446-450, 2002.

[4] B. T. Zhu and M. Yang, "Collapse of a piled industrial building due to surcharge loads," in Proceedings of the 6th International Conference on Tall Buildings (ICTBVI), Singapore, December 2005.

[5] W. D. Wang, Q. Li, Y. Hu, J. W. Shi et al., "Field investigation of collapse of a 13-story high-rise residential building in Shanghai," Journal of Performance of Constructed Facilities, vol. 31, no. 4, Article ID 04017012, 2017.

[6] E. A. Ellis and S. M. Springman, "Modelling of soil-structure interaction for a piled bridge abutment in plane strain FEM analyses," Computers and Geotechnics, vol. 28, no. 2, pp. 79-98, 2001.

[7] M. R. Karim, S.-C. R. Lo, and C. T. Gnanendran, "Behaviour of piles subjected to passive loading due to embankment construction," Canadian Geotechnical Journal, vol. 51, no. 3, pp. 303-310, 2014.

[8] J. L. Zheng, J. H. Zhang, and X. F. Li, "Effects of embankment load on piled bridge abutments on soft clay," China Journal of Highway and Transport, vol. 26, no. 2, pp. 48-55, 2013.

[9] A. T. C. Goh, C. I. Teh, and K. S. Wong, "Analysis of piles subjected to embankment induced lateral soil movements," Journal of Geotechnical and Geoenvironmental Engineering, vol. 123, no. 9, pp. 792-801, 1997.

[10] D. P. Stewart, R. J. Jewell, and M. F. Randolph, "Numerical modelling of piled bridge abutments on soft ground," Computers and Geotechnics, vol. 15, no. 1, pp. 21-46, 1993.

[11] H. G. Poulos and E. H. Davis, Pile Foundation Analysis and Design, John Wiley and Sons, New York, NY, USA, 1980.

[12] D. P. Stewart, R. J. Jewell, and M. F. Randolph, "Design of piled bridge abutments on soft clay for loading from lateral soil movements," Géotechnique, vol. 44, no. 2, pp. 277-296, 1994.

[13] Y. K. Chow, "Analysis of piles used for slope stabilization," International Journal for Numerical and Analytical Methods in Geomechanics, vol. 20, no. 9, pp. 635-646, 1996.

[14] F. Y. Liang, F. Yu, J. B. Li et al., "Analysis of bearing capacity of a single pile under adjacent building subjected to lateral soil movements," Rock and Soil Mechanics, vol. 31, no. 2, pp. 449-454, 2010.

[15] M. K. Kelesoglu and S. F. Cinicioglu, "Free-field measurements to disclose lateral reaction mechanism of piles subjected to soil movements," Journal of Geotechnical and Geoenvironmental Engineering, vol. 136, no. 2, pp. 331-343, 2010.

[16] M. Ashour and H. Ardalan, "Analysis of pile stabilized slopes based on soil-pile interaction," Computers and Geotechnics, vol. 39, pp. 85-97, 2012.

[17] W. D. Guo, "Elastic models for nonlinear response of rigid passive piles," International Journal for Numeriacl and Analytical Methods in Geomechanics, vol. 38, no. 18, pp. 19691989, 2014.

[18] S. Muraro, A. Madaschi, and A. Gajo, "On the reliability of 3D numerical analyses on passive piles used for slope stabilisation in frictional soils," Géotechnique, vol. 64, no. 6, pp. 486-492, 2014.

[19] H. Zhang, M. L. Shi, W. S. Hu et al., "Analysis of sloping pier nearby embankment of overpass bridge in interchange," Journal of Southeast University (Natural Science Edition), vol. 43, no. 3, pp. 617-623, 2013.

[20] H. Matlock, "Correlations for design of laterally loaded piles in soft clay," in Proceedings of the 2nd Annual Offshore Technology Conference, Houston, TX, USA, April 1970.
[21] Y.-m. Hsiung, "Theoretical elastic-plastic solution for laterally loaded piles," Journal of Geotechnical and Geoenvironmental Engineering, vol. 129, no. 5, pp. 475-480, 2003.

[22] W. D. Guo, "Simple model for nonlinear response of 52 laterally loaded piles," Journal of Geotechnical and Geoenvironmental Engineering, vol. 139, no. 2, pp. 234-252, 2012.

[23] L. Zhang, "Nonlinear analysis of laterally loaded rigid piles in cohesionless soil," Computers and Geotechnics, vol. 36, no. 5, pp. 718-724, 2009.

[24] L. Zhang and S. Ahmari, "Nonlinear analysis of laterally loaded rigid piles in cohesive soil," International Journal for Numerical and Analytical Methods in Geomechanics, vol. 37, no. 2, pp. 201-220, 2013.

[25] T. Ito and T. Matsui, "Methods to estimate lateral force acting on stabilizing piles," Soils and Foundations, vol. 15, no. 4, pp. 43-59, 1975.

[26] M. X. Zhu, W. M. Gong, G. P. Xu et al., "Analysis of bearing mechanism of axially loaded isolation piles under large-scale surcharge loading," Chinese Journal of Rock Mechanics and Engineering, vol. 33, no. 2, pp. 421-432, 2014.

[27] Z. J. Shen, "Stabilizing force and design method for anti-slide piles," Chinese Journal of Geotechnical Engineering, vol. 14, no. 1, pp. 51-56, 1992.

[28] W. D. Guo, "On limiting force profile, slip depth and response of lateral piles," Computers and Geotechnics, vol. 33, no. 1, pp. 47-67, 2006.

[29] L. Zhang, X. N. Gong, and J. L. Yu, "Analysis of deformation and internal force for single pile under combined vertical and lateral loads considering yielding of soil," Rock and Soil Mechanics, vol. 32, no. 8, pp. 2441-2446, 2011.

[30] M. H. Zhao, L. G. Wu, and J. H. Liu, "Finite difference solution for loadbearing and anti-slide pile with consideration of P- $\Delta$ effect," Engineering Mechanics, vol. 25, no. 3, pp. 102-106, 2008.

[31] M. Zhu, Y. Zhang, W. Gong et al., "Generalized solutions for axially and laterally loaded piles in multilayered soil deposits with transfer matrix method," International Journal of Geomechanic, vol. 17, no. 4, Article ID 04016104, 2016.

[32] C.-D. Wang, "Lateral stress caused by horizontal and vertical surcharge strip loads on a cross-anisotropic backfill," International Journal for Numerical and Analytical Methods in Geomechanics, vol. 29, no. 14, pp. 1341-1361, 2005.

[33] T. Nogami and S. K. Paulson, "Transfer matrix approach for nonlinear pile group response analysis," International Journal for Numerical and Analytical Methods in Geomechanics, vol. 9, no. 4, pp. 299-316, 1985.

[34] Q. T. Liu and G. R. Ni, Transfer Matrix Approach for Structure Analysis, Railway Publishing House Co., Ltd., Beijing, China, 1997.

[35] L. Zhang, M. H. Zhao, and X. J. Zou, "Behavior of laterally loaded piles in multilayered soils," International Journal of Geomechanic, vol. 15, no. 2, Article ID 06014017, 2015.

[36] A. W. Skempton, "The bearing capacity of clays," in Proceedings of the Building Research Congress, London, England, January 1951.

[37] A. J. Zhang, Model of interaction between pile and soil \& simplified calculating method of pile used to stability unstable slope, PhD. thesis, South China University of Technology, Guangzhou, China, 2013. 